\title{
The Skull Vibration-Induced Nystagmus Test of Vestibular Function-A Review
}

\author{
Georges Dumas ${ }^{1,2 *}$, Ian S. Curthoys ${ }^{3}$, Alexis Lion ${ }^{2,4}$, Philippe Perrin ${ }^{2,5}$ and \\ Sébastien Schmerber ${ }^{1,6}$
}

${ }^{1}$ Department of Oto-Rhino-Laryngology, Head and Neck Surgery, University Hospital, Grenoble, France, ${ }^{2} E A 3450$ DevAH, Development, Adaptation and Disadvantage, Faculty of Medicine and UFR STAPS, University of Lorraine, Villers-lès-Nancy, France, ${ }^{3}$ Vestibular Research Laboratory, School of Psychology, the University of Sydney, Sydney, NSW, Australia, ${ }^{4}$ Sports Medicine Research Laboratory, Luxembourg Institute of Health, Strassen, Luxembourg, ${ }^{5}$ Department of Paediatric Oto-Rhino-Laryngology, University Hospital of Nancy, Vandoeuvre-lès-Nancy, France, ${ }^{6}$ INSERM UMR 2015, Grenoble, France

\section{OPEN ACCESS}

Edited by:

Richard Lewis,

Harvard University, USA

Reviewed by:

Bernard Cohen,

Icahn School of Medicine at Mount

Sinai, USA

Shinichi Iwasaki,

University of Tokyo, Japan

*Correspondence:

Georges Dumas

GDumas@chu-grenoble.fr

Specialty section: This article was submitted to Neuro-otology, a section of the journal

Frontiers in Neurology

Received: 18 August 2016 Accepted: 30 January 2017

Published: 09 March 2017

Citation:

Dumas G, Curthoys IS, Lion A, Perrin P and Schmerber S (2017)

The Skull Vibration-Induced

Nystagmus Test of Vestibular

Function-A Review.

Front. Neurol. 8:41.

doi: 10.3389/fneur.2017.00041
A $100-\mathrm{Hz}$ bone-conducted vibration applied to either mastoid induces instantaneously a predominantly horizontal nystagmus, with quick phases beating away from the affected side in patients with a unilateral vestibular loss (UVL). The same stimulus in healthy asymptomatic subjects has little or no effect. This is skull vibration-induced nystagmus (SVIN), and it is a useful, simple, non-invasive, robust indicator of asymmetry of vestibular function and the side of the vestibular loss. The nystagmus is precisely stimulus-locked: it starts with stimulation onset and stops at stimulation offset, with no post-stimulation reversal. It is sustained during long stimulus durations; it is reproducible; it beats in the same direction irrespective of which mastoid is stimulated; it shows little or no habituation; and it is permanent-even well-compensated UVL patients show SVIN. A SVIN is observed under Frenzel goggles or videonystagmoscopy and recorded under videonystagmography in absence of visual-fixation and strong sedative drugs. Stimulus frequency, location, and intensity modify the results, and a large variability in skull morphology between people can modify the stimulus. SVIN to $100 \mathrm{~Hz}$ mastoid stimulation is a robust response. We describe the optimum method of stimulation on the basis of the literature data and testing more than 18,500 patients. Recent neural evidence clarifies which vestibular receptors are stimulated, how they cause the nystagmus, and why the same vibration in patients with semicircular canal dehiscence (SCD) causes a nystagmus beating toward the affected ear. This review focuses not only on the optimal parameters of the stimulus and response of UVL and SCD patients but also shows how other vestibular dysfunctions affect SVIN. We conclude that the presence of SVIN is a useful indicator of the asymmetry of vestibular function between the two ears, but in order to identify which is the affected ear, other information and careful clinical judgment are needed.

Keywords: skull vibration, nystagmus, vertigo, high frequencies, vestibular disease

Abbreviations: BCV, bone-conducted vibration; SCC, semicircular canal; SPV, slow-phase eye velocity; SVIN, skull vibrationinduced nystagmus; SVINT, skull vibration-induced nystagmus test; UVL, unilateral vestibular loss; pUVL, partial unilateral vestibular loss; tUVL, total unilateral vestibular loss; VOR, vestibulo-ocular reflex. 


\section{INTRODUCTION-HISTORICAL BACKGROUND}

Von-Bekesy in 1935 (1) reported that vibration applied to the skull induced reflexes and motion illusions which he attributed to stimulation of vestibular receptors. Lucke in 1973 (2) first described how $100 \mathrm{~Hz}$ mastoid vibration-induced nystagmus (VIN) in a patient with a unilateral vestibular loss (UVL), and in 1999 that result was confirmed and extended by Hamann and Schuster (3) and Dumas et al. (4, 5). Dumas et al. described a systematic clinical analysis of the skull vibration-induced nystagmus (SVIN) in patients after total (tUVL) [after surgery for vestibular schwannoma (VS)] or partial (pUVL) UVL and reported more recently SVIN in superior semicircular canal dehiscence (SCD) patients $(6,7)$.

Shortly after Lucke's observation, Young et al. (8) reported that squirrel monkey primary afferents from semicircular canals (SCC) and otoliths were activated by bone-conducted vibration (BCV). That report presaged the likely explanation of SVIN and the neural basis of SVIN is considered below.

Vibration-induced nystagmus has been described in various inner ear diseases (Table 1); most publications address cranial BCV stimulations $(2-7,9-25,27-29,41-43,45)$ but others deal with cervical and cranial vibrations $(26,30,31)$ and a few with cervical stimulations only $(32-34,40,44)$. This review is only mainly restricted to $\mathrm{BCV}$ with cranium stimulations which are now more clearly documented by physiology (35-39). We propose for clarity to term it the skull vibration-induced nystagmus test (SVINT).

\section{METHODS-PRACTICAL CONDITIONS}

\section{Test Procedure}

The examiner performs stimulation either by standing in front of (or behind) the patient to use his dominant hand for more reproducibility $(46,47)$. The vibrator must be firmly held and applied perpendicularly to the skin over the mastoid process, posteriorly to the auricle, at the level of the external acoustic meatus (Figure 1). Stimulation applied on the tip of the mastoid process must be avoided, as it can induce activation of proprioceptive afferents from the trapezius and sternocleidomastoid muscles (47). A pressure of about $10 \mathrm{~N}$ is applied. It is recommended that three stimulation trials of each mastoid be given using $100 \mathrm{~Hz}$ with each stimulus lasting about 5-10 s. Eye movements can be visualized either under Frenzel goggles or, preferably, observed using video procedures such as videonystagmoscopy or recorded under videonystagmography $2 \mathrm{D}$ or $3 \mathrm{D}$. Testing must be done in complete absence of any visual fixation of either eye (47). The average slow-phase velocity (SPV) of SVIN after tUVL is $10.83 \%$ $(\mathrm{SD}=6.82 ; n=45)(10,26)$. The simplest procedure is to use only mastoid stimulation as described above $(3,12,23,24)$; one may use also vertex stimulation $(4,26,29)$. The technical and practical conditions of the test are presented in Figure 1.

\section{Stimulation}

Different vibrators are available [VVIB 3F or VVIB $100 \mathrm{~Hz}$ (Synapsys, France) or ISV 1 or IP 500 (Amplifon, France) or
VVSED 500 (Euro Clinic, Italy) or NC 70209 (North Coast Medical, USA)] (Figure 1). The vibrator should preferably have a circular contact surface $20 \mathrm{~mm}$ in diameter covered with a thin felt or thin rubber.

Pressure and acceleration measures have shown that for optimum mastoid stimulation the force should be around $10 \mathrm{~N}$ or $1 \mathrm{~kg}$ (46). For such mastoid stimulation the spread or radiation of vibration to neck muscles is small (46). Figure 2 shows the SVINT topographic optimization using piezoelectric sensors. Vibration applied to one mastoid is very efficiently transmitted to the opposite mastoid for frequencies under $0.25 \mathrm{kHz}(48-54)$; conversely vertex and cervical stimulations are less efficient for vibrations energy transfer to mastoid (close to the vestibule end organ). A small part of vibrations radiates to cervical region and vice versa.

\section{Stimulus Location}

For most vestibular pathologies, mastoid stimulation elicits higher SVIN SPV than vertex or cervical stimulation $(4,5,9,10$, 19-24, 26). Mastoid stimulation will predominantly stimulate labyrinthine receptors in both labyrinths, with only small stimulation of cervical muscle proprioceptors (46). For the cranial midline location, the comparison of the SVIN SPV measured at the frontal location $(\mathrm{Fz})$, vertex $(\mathrm{Vx})$, bregma, occipital, and sub-occipital locations at 100 and $60 \mathrm{~Hz}$ in 15 UVL patients did not show significant differences (46). BCV applied to the frontal location is considerably less efficient than mastoid vibration in eliciting SVIN (26) and for vibration transfer to the promontory (54-56).

However, in cases of SCD or other pathologies associated with a third window, vertex stimulation is more efficient than mastoid stimulation (7). This may occur because the pressure transmission from cerebrospinal fluid (via middle temporal fossa fistula) is enhanced in this condition $(50,57,58)$.

\section{Stimulus Frequency}

In measures on patients with tUVL, a large range of frequencies $(40-150 \mathrm{~Hz})$ have been shown to induce SVIN. Stimulation at $20 \mathrm{~Hz}$ is not effective, and progressively stronger responses are obtained for stimuli between 60 to $120 \mathrm{~Hz}$ (28), with around $100 \mathrm{~Hz}$ being optimal. In clinical practice, the frequency of stimulation used by Karlberg et al. (13) was $92 \mathrm{~Hz}$, Lackner and Graybiel (11) was $120 \mathrm{~Hz}$, and Magnusson et al. (31) was $85 \mathrm{~Hz}$, and it was $100 \mathrm{~Hz}$ for the following: Manzari et al. (42), Ohki et al. (12), Park et al. (24), Koo et al. (19), Xie at al (20), and Dumas et al. (27).

In patients with pUVL, similar results are observed but with significant smaller slow-phase eye velocities (SPV) of SVIN. SVIN SPV were significantly higher at $100 \mathrm{~Hz}$ and $60 \mathrm{~Hz}$ than at $30 \mathrm{~Hz}$ (27). Recently our group has shown SPV was optimal at $100 \mathrm{~Hz}$ by testing SVIN frequencies from 10 to $700 \mathrm{~Hz}$ delivered by a Bruel \& Kjaer Minishaker 4810 (Naerum, Denmark) in 15 common and severe UVL patients. No responses were observed at 10 or $500 \mathrm{~Hz}$. 
TABLE 1 | Synoptic table of results in literature.

\begin{tabular}{|c|c|c|c|c|c|c|c|c|}
\hline Reference & $\begin{array}{l}\text { Level of } \\
\text { evidence }\end{array}$ & $\begin{array}{l}\text { Study } \\
\text { design }\end{array}$ & $\begin{array}{l}\text { Sample } \\
\text { size }(n)\end{array}$ & Pathology & Record & Stimulus location & $\begin{array}{l}\text { Stimulus frequency } \\
\mathrm{Hz} \text { (amplitude } \mathrm{mm} \text { ) }\end{array}$ & Main contribution, comments \\
\hline Lücke 1973 (2) & 3 & RCS & 65 & $\begin{array}{l}\text { Unilateral vestibular } \\
\text { loss (UVL) patients, } \\
\text { central patients }\end{array}$ & Frenzel & $\begin{array}{l}\text { Face cranium vertex } \\
\text { necknape }\end{array}$ & 100 & $\begin{array}{l}\text { First incidental observation of a vibration-induced nystagmus } \\
\text { (VIN) in a UVL patient }\end{array}$ \\
\hline $\begin{array}{l}\text { Lackner and } \\
\text { Graybiel } 1974 \text { (11) }\end{array}$ & 2 & PCS & 6 & Normal subjects & Frenzel & $\begin{array}{l}\text { Face, mastoids, } \\
\text { cervical }\end{array}$ & $\begin{array}{l}\text { 40-280 optimal } \\
120-180\end{array}$ & $\begin{array}{l}\text { Vibrations induce postural, visual illusions, rare VIN in normal } \\
\text { subjects }\end{array}$ \\
\hline $\begin{array}{l}\text { Yagi and Ohyama } \\
1996(32)\end{array}$ & 3 & PCS & 11 & UVL & VNG3D & Dorsal neck muscles & $115(1 \mathrm{~mm})$ & $\begin{array}{l}\text { Vibrations induce in UVL compensated patients a VIN (Hor and } \\
\text { Vert components) related to vestibular decompensation }\end{array}$ \\
\hline \multirow{2}{*}{$\begin{array}{l}\text { Strupp et al. } 1998 \\
\text { (33) }\end{array}$} & \multirow[t]{2}{*}{2} & \multirow[t]{2}{*}{ PCS } & 25 & VN & \multirow[t]{2}{*}{ VNG, SVSA } & \multirow[t]{2}{*}{ Neck muscles } & \multirow[t]{2}{*}{100} & \multirow[t]{2}{*}{ Somatosensory substitution of vestibular function in UVL patients } \\
\hline & & & 25 & Controls & & & & \\
\hline \multirow{2}{*}{$\begin{array}{l}\text { Popov et al. } 1999 \\
(40)\end{array}$} & \multirow[t]{2}{*}{2} & \multirow[t]{2}{*}{ PCS } & 4 & UVL & \multirow{2}{*}{$\begin{array}{l}\text { Scleral, coils, } \\
\text { visual illusions }\end{array}$} & \multirow[t]{2}{*}{ Neck vibration } & \multirow[t]{2}{*}{$90(0.5 \mathrm{~mm})$} & \multirow{2}{*}{$\begin{array}{l}\text { Propriogyral illusion secondary to vibration-induced eye } \\
\text { movement (COR) }\end{array}$} \\
\hline & & & 5 & Controls & & & & \\
\hline \multirow[t]{2}{*}{$\begin{array}{l}\text { Hamann and } \\
\text { Schuster } 1999 \text { (3) }\end{array}$} & \multirow[t]{2}{*}{3} & \multirow[t]{2}{*}{ RCS } & 60 & $\begin{array}{l}\text { Peripheral UVL } \\
\text { benign positional } \\
\text { paroxystic vertigo }\end{array}$ & \multirow[t]{2}{*}{ VNS VNG2D } & \multirow[t]{2}{*}{ Mastoid } & \multirow[t]{2}{*}{60,100} & \multirow[t]{2}{*}{$\begin{array}{l}\text { In UVL, a lesionnal VIN is observed in peripheral diseases and } \\
\text { seldom in BPPV and in central patients. Optimal stim } 60 \mathrm{~Hz}\end{array}$} \\
\hline & & & 40 & BSL & & & & \\
\hline \multirow[t]{3}{*}{$\begin{array}{l}\text { Dumas et al. } 1999 \\
\text { (4) }\end{array}$} & \multirow[t]{3}{*}{3} & \multirow[t]{3}{*}{ RCS } & 80 & $\begin{array}{l}\text { UVL: TUVL (TA, VNT) } \\
\text { PUVL (MD, VN, VS) }\end{array}$ & \multirow[t]{3}{*}{ VNS, VNG3D } & \multirow[t]{3}{*}{ Mastoid, vertex } & \multirow[t]{3}{*}{$100(0.2 \mathrm{~mm})$} & \multirow[t]{3}{*}{$\begin{array}{l}\text { VIN: } 3 \text { components in TUVL. VIN characteristics, technical } \\
\text { conditions, sensitivity, specificity }\end{array}$} \\
\hline & & & 10 & BSL & & & & \\
\hline & & & 100 & Controls & & & & \\
\hline \multirow{2}{*}{$\begin{array}{l}\text { Dumas et al. } 2000 \\
\text { (5) }\end{array}$} & \multirow[t]{2}{*}{3} & \multirow[t]{2}{*}{ RCS } & 46 & UVL & \multirow[t]{2}{*}{ VNS, VNG3D } & \multirow[t]{2}{*}{ Mastoid, vertex } & \multirow[t]{2}{*}{$20-150(0.2 \mathrm{~mm})$} & VIN SPV amplitude; location and frequency stimulus optimization. \\
\hline & & & 105 & Controls & & & & \\
\hline $\begin{array}{l}\text { Karlberg et al. } \\
2003(13)\end{array}$ & 3 & PCS & 18 & UVL (VN, VNT) & Scleral Coils, SVH & $\begin{array}{l}\text { Mastoid, posterior } \\
\text { neck }\end{array}$ & $92(0.6 \mathrm{~mm})$ & $\begin{array}{l}\text { SVH shift is explained by vibration-induced ocular torsion whose } \\
\text { magnitude is related to the extent of UVL deficit }\end{array}$ \\
\hline $\begin{array}{l}\text { Ohki et al. } 2003 \\
\text { (12) }\end{array}$ & 3 & RCS & 100 & UVL (VN, MD, VS) & VNG & Mastoid, forehead & 100 & In UVL patients VIN is correlated with CaT hypofunction \\
\hline Nuti and Mandala & 3 & RCS & 28 & $\mathrm{VN}$ & VNG & Mastoid & $60-120$ & Sensitivity $75 \%$, specificity $100 \%$ VIN beats usually toward the \\
\hline $2005(21)$ & & & 25 & Controls & & & & Intact side \\
\hline $\begin{array}{l}\text { Magnusson et al. } \\
2006 \text { (31) }\end{array}$ & 2 & PCS & 10 & Normal subjects & Posture & Mastoid, neck & $\begin{array}{l}85(1 \mathrm{~mm}) \\
55(0.4 \mathrm{~mm})\end{array}$ & $\begin{array}{l}\text { Cervical muscle afferents play a dominant role over vestibular } \\
\text { afferents during bilateral vibration of the neck }\end{array}$ \\
\hline $\begin{array}{l}\text { Dumas et al. } 2007 \\
\text { (10) }\end{array}$ & 3 & RCS & 4,800 & $\begin{array}{l}\text { TUVL, PUVL, } \\
\text { brainstem lesion }\end{array}$ & VNS, VNG & Mastoid, vertex & $100(1 \mathrm{~mm})$ & VIN is observed in 98\% TUVL,75\% PUVL, 34\% BSL \\
\hline
\end{tabular}




\section{TABLE 1 | Continued}

\begin{tabular}{|c|c|c|c|c|c|c|c|c|}
\hline Reference & $\begin{array}{l}\text { Level of } \\
\text { evidence }\end{array}$ & $\begin{array}{l}\text { Study } \\
\text { design }\end{array}$ & $\begin{array}{l}\text { Sample } \\
\text { size }(n)\end{array}$ & Pathology & Record & Stimulus location & $\begin{array}{l}\text { Stimulus frequency } \\
\mathrm{Hz} \text { (amplitude } \mathrm{mm} \text { ) }\end{array}$ & Main contribution, comments \\
\hline $\begin{array}{l}\text { Hong et al. } 2007 \\
\text { (22) }\end{array}$ & 3 & RCS & 52 & MD Unilat & $\begin{array}{l}\text { VNS, VNG, head- } \\
\text { shaking-nystagmus } \\
\text { (HSN), CaT }\end{array}$ & Mastoid & 100 & $\begin{array}{l}\text { VIN is usually correlated with CaT hypofunction. VIN beats } \\
\text { frequently ipsilaterally toward MD side }\end{array}$ \\
\hline $\begin{array}{l}\text { White et al. } 2007 \\
(41)\end{array}$ & 3 & RCS & 8 & SCD & VNS, VNG 2D & $\begin{array}{l}\text { Mastoid, vertex, } \\
\text { suboccip. }\end{array}$ & 100 & $\begin{array}{l}\text { Vibrations induce a torsional VIN beating toward the SCD and } \\
\text { down beating suggesting the stimulation of the dehiscent SSCC }\end{array}$ \\
\hline \multirow{2}{*}{$\begin{array}{l}\text { Dumas et al. } 2008 \\
\text { (26) }\end{array}$} & \multirow[t]{2}{*}{3} & \multirow[t]{2}{*}{ RCS } & 131 & TUVL (TA, VNT) & \multirow[t]{2}{*}{ VNS, VNG 2D 3D } & \multirow{2}{*}{$\begin{array}{l}\text { Mastoid, vertex } \\
\text { (cervical) }\end{array}$} & \multirow[t]{2}{*}{$100(1 \mathrm{~mm})$} & \multirow{2}{*}{$\begin{array}{l}\text { VIN: } 3 \text { components }(H, V, T), S V I N T \text { : a bilateral stimulation, } \\
\text { sensitivity } 98 \% \text {, specificity } 94 \%, S P V: 10.7 \% \text {; } S D=7.5, \text { VIN is } \\
\text { always beating toward the intact side }\end{array}$} \\
\hline & & & 95 & Controls & & & & \\
\hline $\begin{array}{l}\text { Manzari et al. } 2008 \\
(42)\end{array}$ & 3 & RCS & 16 & SCD & VNG3D & Mastoid & 100 & $\begin{array}{l}\text { Vibrations induce a VIN with a torsional component beating } \\
\text { toward the lesion side }\end{array}$ \\
\hline \multirow[t]{2}{*}{ Park et al. 2008 (23) } & \multirow[t]{2}{*}{3} & \multirow[t]{2}{*}{ RCS } & 19 & VN & \multirow[t]{2}{*}{ VNG } & \multirow[t]{2}{*}{ Mastoid } & \multirow[t]{2}{*}{100} & \multirow[t]{2}{*}{ Clinical significance of VIN } \\
\hline & & & 22 & Controls & & & & \\
\hline $\begin{array}{l}\text { Park et al. } 2010 \\
\text { (24) }\end{array}$ & 2 & PCS & 26 & VN & VNG & Mastoid & 100 & VIN clinical significance, reliability \\
\hline Aw et al. 2011 (43) & 3 & RCS & 17 & SCD & Scleral coils & Mastoid & 500 & $\begin{array}{l}\text { Eye slow torsional component ViVOR is directed toward the intact } \\
\text { side: vibrations stimulate the anterior dehiscent canal }\end{array}$ \\
\hline $\begin{array}{l}\text { Dumas et al. } 2011 \\
\text { (27) }\end{array}$ & 3 & RCS & 99 & $\begin{array}{l}\text { PUVL (VN, VS, } \\
\text { MD, CL) }\end{array}$ & VNG 2D & Mastoid, vertex & 30, 60, 100 (1 mm) & $\begin{array}{l}\text { Sensitivity } 75 \% \text {. VIN beats toward safe side in } 91 \% \text {. skull } \\
\text { vibration-induced nystagmus test complements CaT, HST in } \\
\text { vestibular multifrequential analysis }\end{array}$ \\
\hline Kawase 2011 (44) & 3 & RCS & 14 & $\begin{array}{l}7 \text { pre-surgical VS, } 7 \\
\text { post-surgical VS }\end{array}$ & VNG, SWV & Neck muscles & 110 & $\begin{array}{l}\text { Ipsilat. vibrations increase SW deviation, VIN is correlated to SW } \\
\text { alteration, VIN is not modified by the side of the stimulation }\end{array}$ \\
\hline \multirow[t]{2}{*}{$\begin{array}{l}\text { Koo et al. } 2011 \\
\text { (19) }\end{array}$} & \multirow[t]{2}{*}{3} & \multirow[t]{2}{*}{ RCS } & 74 & VS & VNG & \multirow[t]{2}{*}{ Mastoid } & \multirow[t]{2}{*}{100} & $\begin{array}{l}\text { Comparison of sensitivity of VIN and other vestibular tests in the } \\
\text { YAW axis in VN. VIN is observed in } 86 \% \text { of cases in correlation } \\
\text { with CaT Hypofunction. VIN beats toward the intact side in } 98 \%\end{array}$ \\
\hline & & & 24 & Controls & HST CaT & & & $\begin{array}{l}\text { VIN is observed in } 86 \% \text { of cases in correlation with CaT } \\
\text { Hypofunction. VIN beats toward the intact side in } 98 \%\end{array}$ \\
\hline \multirow[t]{2}{*}{$\begin{array}{l}\text { Dumas et al. } 2013 \\
\text { (30) }\end{array}$} & \multirow[t]{2}{*}{2} & \multirow[t]{2}{*}{ RCS } & 9 & $\begin{array}{l}\text { Profound } \\
\text { compensated long- } \\
\text { standing UVL }\end{array}$ & \multirow[t]{2}{*}{ VNG 2D, posturog } & \multirow[t]{2}{*}{$\begin{array}{l}\text { Mastoid, vertex } \\
\text { (cervical) }\end{array}$} & \multirow[t]{2}{*}{100} & \multirow[t]{2}{*}{$\begin{array}{l}\text { VIN beats toward the intact side in } 100 \% \text { of cases, No } \\
\text { measurable postural changes in EC condition in long standing } \\
\text { compensated severe UVL patients }\end{array}$} \\
\hline & & & 12 & Control & & & & \\
\hline \multirow[t]{2}{*}{ Xie et al. 2013 (20) } & \multirow[t]{2}{*}{3} & \multirow[t]{2}{*}{ RCS } & 112 & UVL & \multirow[t]{2}{*}{ VNG, HST CaT } & \multirow[t]{2}{*}{ Mastoids } & \multirow[t]{2}{*}{100} & $\begin{array}{l}\text { VIN is observed in } 91 \% \text { of peripheral UVL. It is more frequent and } \\
\text { important when CaT canal paresis augments. VIN usually beats } \\
\text { toward the healthy side except in MD }\end{array}$ \\
\hline & & & 30 & Controls & & & & VIN specificity is $100 \%$ \\
\hline
\end{tabular}




\section{RESULTS - MAIN LEADS FOR INTERPRETATION (Box 1)}

In tUVL patients, $100 \mathrm{~Hz} B C V$ applied to either mastoid induces a low velocity $\left(\sim 10^{\circ} / \mathrm{s}\right)$ predominantly horizontal nystagmus beating away from the affected side, irrespective of which mastoid is stimulated $(3-5,9,10,13,26)$ (Figure 3). The nystagmus is precisely stimulus-locked: it starts with stimulation onset and stops at stimulation offset, with no post-stimulation reversal and is reproducible.

\section{SVIN Habituation or Fatigue after Long Period of Stimulation in tUVL}

Three-dimensional recordings of $100-\mathrm{Hz}$ long duration SVIN in tUVL patients during stimulation lasting $3 \mathrm{~min}$ demonstrated that the SVIN horizontal component persisted during stimulation with little SPV decrease, whereas first the vertical and then torsional components disappeared. These results suggest a moderate per-stimulatory adaptation (28). The brief repeated stimulation in the usual test does not show signs of habituation.

\section{SVIN Acts as a Vestibular Weber Test}

In tUVL, for $100 \mathrm{~Hz} \mathrm{BCV}$ mastoid stimulation, SVIN is observed in $98 \%$ of patients and beats toward the healthy side in $100 \%$ of cases (26). In addition, there was no correlation between the SVIN SPV value and which side was stimulated-either mastoid was equally effective in generating the SVIN $(P=0.17 ; n=20)$. These results indicate that SVIN is due to stimulation of vestibular receptors on the intact side (26), and in this way, SVIN is a "vestibular Weber test" $(5,10,27)$ (Figure 3$)$. In accord with that description: in total bilateral vestibular lesions (26) and in symmetrical partial bilateral vestibular lesions, no SVIN was observed (27). Similar results are observed in severe pUVL as showed in Figure 4.

\section{Arguments for SVIN Being a Global Vestibular Stimulus}

Three-dimensional eye movement recordings show that the response to SVIN is not purely horizontal (Figure 3). In 43 tUVL patients $(10,26) 100 \mathrm{~Hz}$ mastoid stimulation, the 3D recordings revealed a SVIN with horizontal, torsional, and vertical component in 98,75 , and $47 \%$ of cases, respectively. These observations suggest a primary participation of the horizontal SCC and/or utricle (for generating the horizontal component), of the posterior or superior SCC and/or sacculus (for the vertical component) and superior and posterior SCC and/or otolithic structures (for the torsional component). In SCD (7), the SVIN revealed a primarily torsional, a primarily horizontal, and a primarily vertical (up-beating in $80 \%$ of cases) component in 40,30 , and $30 \%$ of cases, respectively. These results suggest that the superior dehiscent SCC is not the only stimulated structure (the up-beating vertical component suggests the possible stimulation of the posterior SCC or sacculus) (7).

\section{SVIN Is Not Influenced by Vestibular Compensation Mechanisms}

Dumas et al. observed in $98 \%$ of 131 surgical tUVL patients that $100 \mathrm{~Hz}$ mastoid vibration induced a SVIN. In well-compensated 

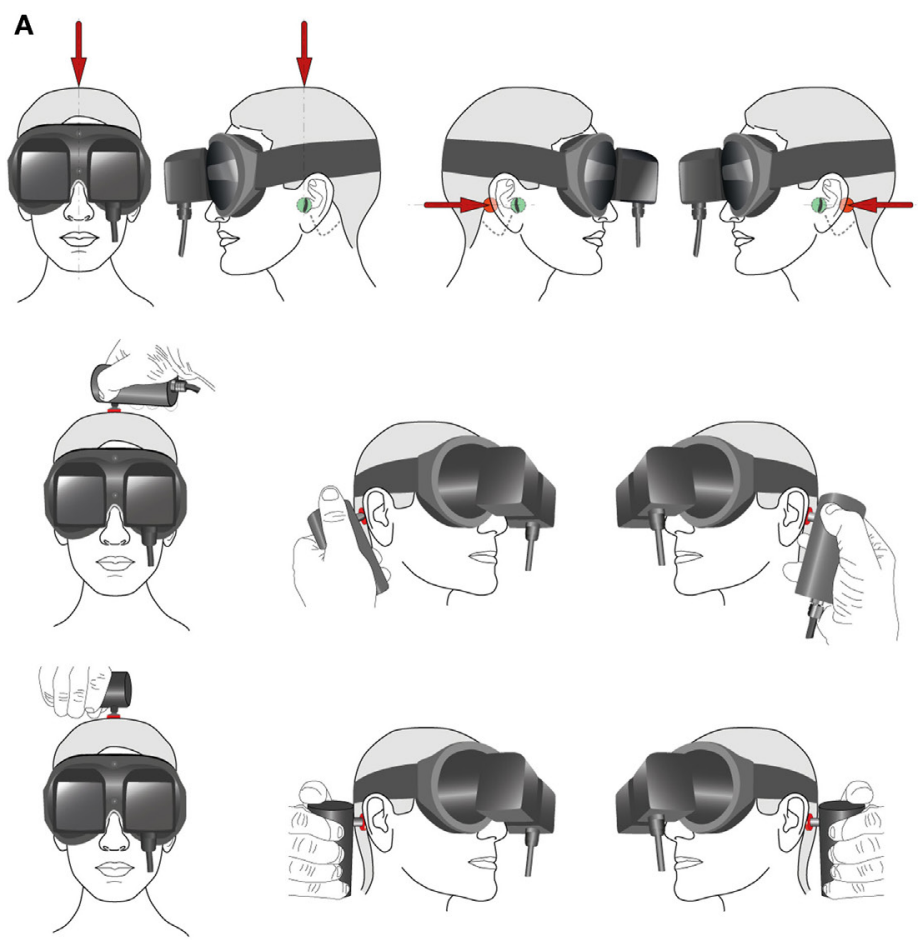

B

FIGURE 1 | Skull vibration-induced nystagmus test technique in clinical practice. (A) Principle of stimulation: the examiner can face the subject, as in the first example. The vibrator cylindrical contact is applied perpendicularly to the designated surface (red spot) with a pressure of about $10 \mathrm{~N}$ or $1 \mathrm{~kg}$ on the vertex or each mastoid process [level to the external acoustic meatus (Green spot)]. The examiner uses the other hand to maintain and immobilize the subject's head. The same type of stimulation can be performed with the examiner behind the subject (second example situation). Stimulation must avoid the mastoid tip to prevent from muscular vibration radiation and proprioceptive involvement. (B) Mastoid stimulation; examiner in front of the subject; the other hand immobilizes the head. $3 \mathrm{~F}$ Synapsys stimulator (France). Videonystagmoscopic recording (Collin ORL, France). patients SVIN was not modified at 6 months, or 2 years, or 10 years (Figure 3 ) or up to 23 years post surgery (26). In another study measuring SVIN, the subjective visual vertical (SVV) and postural changes in a population of severe chronic compensated UVL patients (median: $32 \pm 25$ months) revealed a normalization of the SVV and of postural results but persistence in all patients of SVIN (30). Similarly, Hamann and Schuster $(3,59)$ observed that in a series of 14 unilateral unoperated VS, patients had a SVIN in $80 \%$ of cases (most of them had a chronic evolution and complained of no vestibular imbalance and had a compensated vestibular dysfunction). Ohki et al. (12) demonstrated that in 19, unoperated, long lasting VS and 15 long standing VN, a SVIN beating toward the intact side was observed in 60 and $70 \%$ of cases, respectively.

\section{SVINT Sensitivity and Specificity}

The sensitivity of SVIN in tUVL $(n=131)$, pUVL $(n=78)$, and brainstem lesion $(n=36)$ was 98,75 , and $30 \%$, respectively. Specificity was $94 \%$ ( $n=95$ controls) $(10,26,27)$. SVINT is significantly more sensitive for detecting peripheral disease than central brainstem lesions (BSLs) $(P=0.04)(10,27)$ (Figure 5). The presence and direction of SVIN is strongly correlated with caloric hypofunction (26), and a SVIN is observed in 90\% of UVL patients when caloric test hypofunction is higher than $50 \%$ (12).

\section{SVINT Is More Sensitive for Identifying Peripheral Than Central Diseases}

In central or BSLs, Kheradmand and Zee (60) reported a more frequent down-beating SVIN. In BSLs, a SVIN with horizontal components beating toward the healthy side may also be observed (27) as reported by Dumas and Schmerber in cavernous hemangiomas (61). Hamann and Schuster described a SVIN in 10\% of central diseases (3).

\section{SVIN IN VARIOUS PATIENT CONDITIONS}

Table 1 summarizes the clinical evidence of cervical and BCVs on nystagmus. The selection criteria of publications in this comprehensive table are based on the following process.

Data sources: the following search criteria were used from inception through June 2016 in PubMed, Embase, Cochrane Library for key words: Skull/Head Vibrations, VibrationInduced Nystagmus, Bone conducted vibrations, cranial vibrations, cervical vibrations, consequences on posture, vestibule-ocular-reflex (VOR) and subjective visual vertical (SVV), high frequencies, low frequencies, and nystagmus.

Data selection: in total, 1,723 articles were retrieved among which 1,222 satisfied to eligible criteria: vestibular structures 

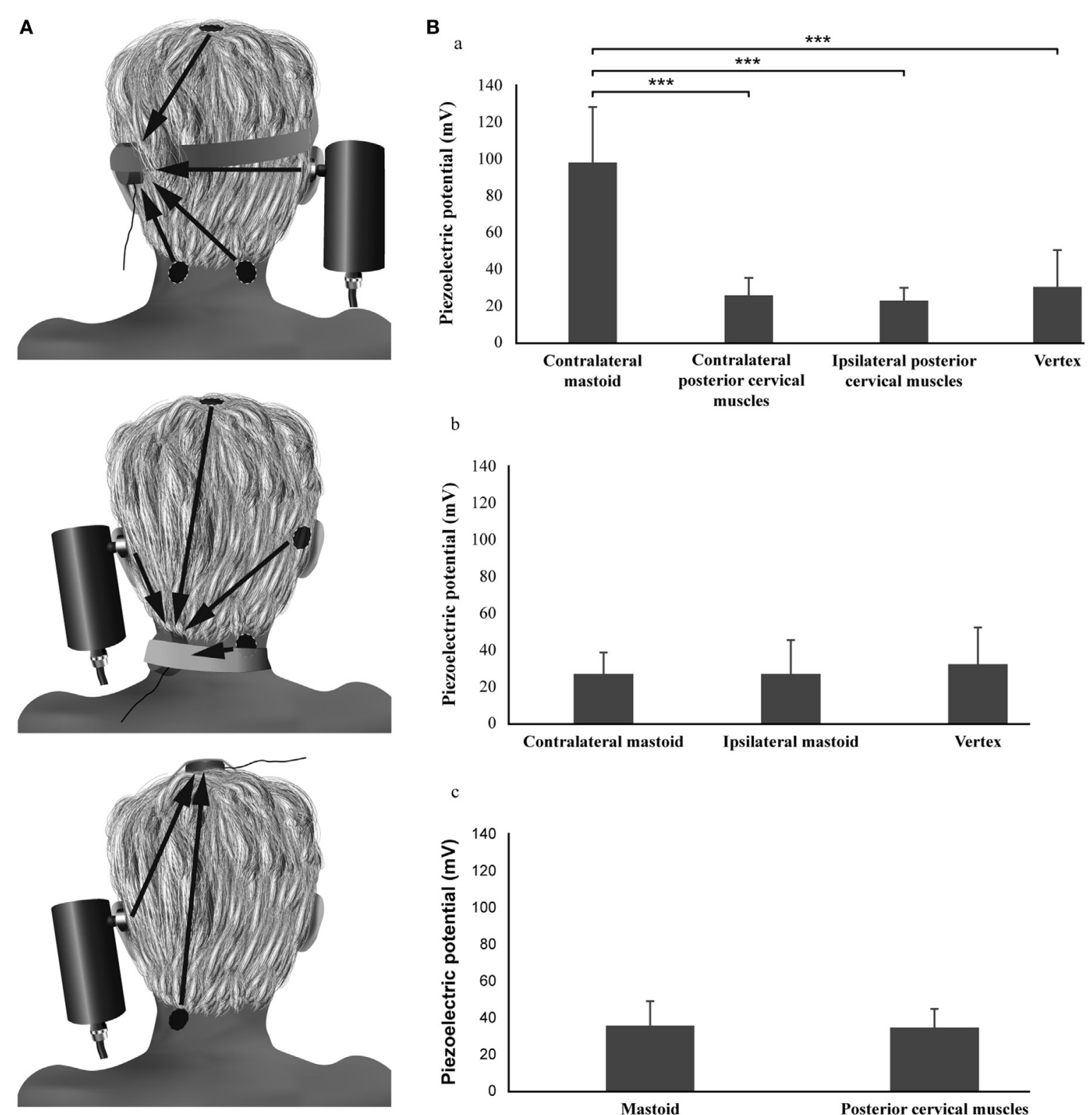

$\mathrm{c}$

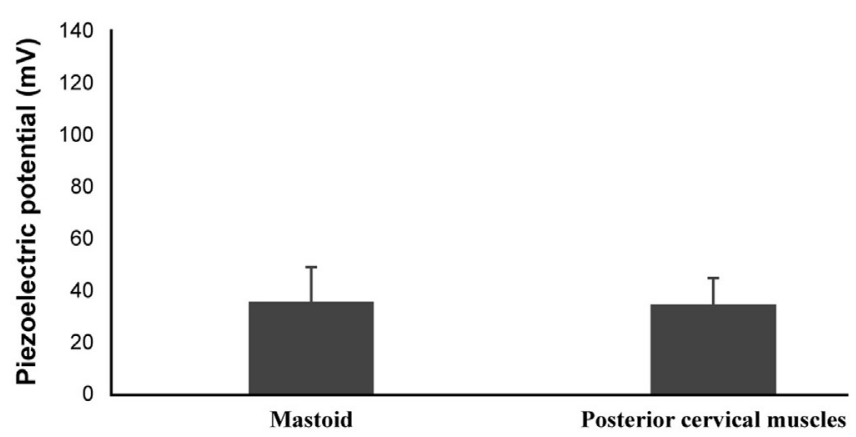

FIGURE 2 | Topographic optimization analysis of the skull vibration-induced nystagmus test. (A) Procedure. (B) Results: the piezoelectric potentials (millivolts) recorded on the mastoid are significantly different according to the location of the stimulation (Friedman test, $P<0.001$ ): the values obtained during the vibratory stimulation of the contralateral mastoid are higher than those obtained after vertex or ipsilateral and contralateral posterior cervical muscle vibrations (Wilcoxon tests, $P<0.001$ ). No difference is observed between vertex and posterior cervical muscle stimulation locations (Wilcoxon tests, $P>0.05)$. The piezoelectric potentials recorded on the vertex or the posterior cervical muscles are not different according to the location of the stimulation (Friedman test and Wilcoxon test, $P>0.05)$.

involved, reproducibility, stimulus frequencies and location optimization, VIN characteristics, comparison with results in caloric test $(\mathrm{CaT})$, ocular vestibular evoked myogenic potential (oVEMP), cervical evoked myogenic potentials (cVEMP), and first level examination tests.

Data extraction: critical appraisal and direct interest retained 29 clinical studies. Were retained series with sufficient number of participants, satisfactory directness of evidence (level 2 or 3), and low risk of bias.
The SVINT reveals instantaneously in UVL patients a vibration-induced nystagmus (SVIN) and so meets the need in clinical practice for a rapid, easy to perform, first-line examination test, completing the battery of common clinical tests exploring low or middle range vestibular frequencies by using higher frequency stimulations at $100 \mathrm{~Hz}$. This test provides clinical guidance for further explorations or imaging as a mild, non-invasive bedside examination test with a valuable cost/ efficiency rate $(47,60,62,63)$. 


\section{BOX 1 | Main clinical outcomes.}

Skull vibration-induced nystagmus (SVIN) optimal frequency stimulation is $100 \mathrm{~Hz}$ and shows a primarily horizontal component; the best location is the mastoid process in most peripheral diseases except in SCD and other labyrinthine pathologies associated with a third window (higher responses are obtained on vertex). Both labyrinths are concomitantly stimulated, and a SVIN beating away from the lesion side is the result of the stimulation of the intact side in tUVL. In partial unilateral vestibular lesions (pUVL), a SVIN beating toward the intact side is usually obtained on mastoid process stimulation. But in SCD, SVIN beats toward the lesion side. The SVIN SPV is correlated in IUVL with the total caloric efficiency on the healthy ear. No responses are observed in bilateral areflexia or symmetrical hypofunctions. The SVIN is definitive and not modified at repetitive controls and long lasting re-tests. The sensitivity is $98 \%$ in tUVL and the specificity $94 \%$ in normal subjects. In pUVL, sensitivity is $75 \%$ and SVIN beats toward the intact side in $91 \%$ of cases. No significant alteration of the vestibulo-spinal reflex analyzed with posturography is observed in chronic compensated unilateral vestibular lesion (UVL) in eye-closed condition. SVIN Test is more sensitive to reveal peripheral than central neurological diseases. A $100 \mathrm{~Hz}$ BCV stimulates both canal and otolith structures in animals but SVIN in clinic is more relevant and is a good marker for canal lesions which it is well correlated to.

In summary, in unilateral peripheral vestibular lesions, SVIN is of the lesional type and beats usually toward the intact side. However, there are exceptions of this rule in partial vestibular lesions related to a combination of responses of the intact side and the residual responses of the lesion side. We report below various clinical situations highlighting these exceptions.

\section{Unilateral Vestibular Loss (UVL)}

Two main goals of SVIN are to indicate the symmetry of the two labyrinths and lesion lateralization. Whereas the evidence is clear that SVIN indicates asymmetry, care must be taken in inferring lateralization of which side is the affected labyrinth.

In tUVL, results are simple, permanent, and consistent: whatever the stimulus frequency $(40-150 \mathrm{~Hz})$ and location on the skull (mastoid or vertex) the quick phase of the resulting SVIN (horizontal and torsional components) beats away from the affected ear and toward the intact side in $98 \%$ of cases (26). Karlberg et al. independently reported similar results after vestibular neurectomy (13). Results are less clear-cut in pUVL.

\section{Total Unilateral Vestibular Loss (tUVL)}

This condition is observed after surgical cases (translabyrinthine approaches, vestibular neurectomy) (Figure 3) or temporal bone fractures.

In tUVL, a SVIN observed in $98 \%$ of patients was always beating toward the intact side (100\% of cases), and the SVIN SPV horizontal component was correlated with the total caloric efficiency on the intact side $(P=0.03 ; n=20)$ (26). These results suggest a predominantly horizontal SCC contribution to SVIN (26) since the caloric test stimulates primarily the horizontal SCC.

In cases of $t U V L$, the axis of eye rotation (i.e., the relative magnitudes of horizontal, torsional, vertical eye velocity) may change with the stimulus location (mastoid or vertex) but the quick phase direction (right or left) remains unchanged with different locations (26). These results correlate closely with those obtained by concomitant caloric and head-shaking test results $(10,26)$.

With less complete unilateral vestibular loss (pUVL), the results are not as clear cut.

\section{Partial Unilateral Vestibular Loss (pUVL)}

A SVIN is observed in $75 \%$ of cases. This condition is observed in vestibular neuritis (VN), Menière's disease, preoperative VSs, and intratympanic gentamicin (ITG).The nystagmus direction beats toward the healthy side in $91 \%$ of those cases (27). In pUVL, SVIN was significantly more frequently observed (90\% of cases) when caloric testing revealed a hypofunction higher than $50 \%(10,12,27)$. Hamann and Schuster suggested that SVIN stimulated the horizontal SCC since they observed a SVIN correlated with the caloric hypofunction but not with CVEMP or SVV results $(3,10)$.

In pUVL explored with caloric (low frequency test at $0.003 \mathrm{~Hz}$ ), HST (midrange frequency at $2 \mathrm{~Hz}$ ), and SVINT (high frequency), it was demonstrated that the three tests were not always positive at the same time. A SVIN was observed in $20 \%$ of patients with normal calorics. Conversely caloric was positive in $22 \%$ of patients with normal SVINT. This was noteworthy in Meniere's Disease (MD) and VS (27). In MD, nystagmus direction observed at $100 \mathrm{~Hz}$ with SVINT may be different from head-shaking-nystagmus (HSN) direction and be associated with a normal caloric test performed on the same day $(10,27,60,64)$. Responses may be different dependent on stimulus frequency (SVIN direction at $30 \mathrm{~Hz}$ is different at 100 $\mathrm{Hz}$ in $10 \%$ of pUVL), and discordant results between caloric test, HST, SVINT are observed in 30\% of pUVL patients (27).

There are other exceptions: reports of $100 \mathrm{~Hz}$ SVIN causing nystagmus beating toward, rather than away from, the affected ear; in 15.5\% Meniere's Disease patients tested, $10 \%$ of $\mathrm{VN}$, and $8 \%$ of pre-surgery VS cases (27). Similar exceptions have been described by Modugno et al. (15), Karkas et al. (16), Hamann and Schuster (3), Freyss et al. (17), and Negrevergne et al. (18).

\section{Superior Semicircular Canal Dehiscence (SCD)}

In contrast to the result in UVL is the result in SCD where the nystagmus beats toward the affected ear, suggesting that the vibration activates the canal with the SCD. In unilateral SCD Dumas et al. (7) reported that the torsional and horizontal quick phases of SVIN beat usually toward the lesion side (Figure 6). In SCD, SVINT is positive in $82 \%$ of cases while caloric and HST are usually negative (7). Other authors (41-43) have also reported in SCD a prevalent stimulation of the superior SCC on the lesion side and observed a torsional SVIN beating toward the lesion side. This result is consistent with the $\mathrm{BC}$ facilitation inherent in this third window pathology (65-69). These results correspond to the acoumetry (Weber test) and the side of the conductive hearing loss as described by our group (7) and confirmed by Park et al. (25).

A SVIN is observed in between 82 and $100 \%$ of SCD patients $(7,41)$. Many authors agree that the stimulation of patients with a dehiscent anterior canal provokes a SVIN 


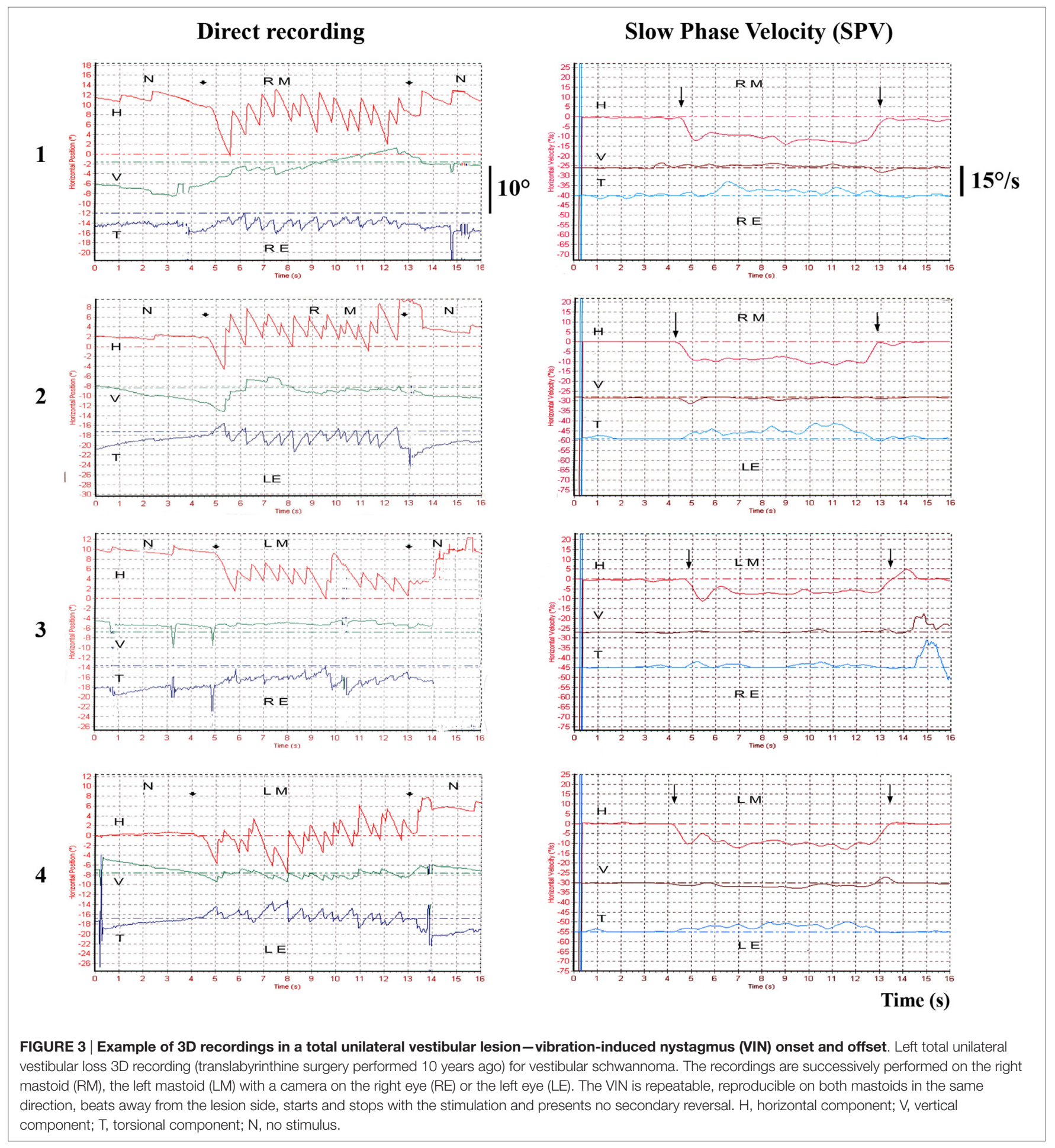

with torsional component beating toward the lesion side (6, 7, 41-43). This is opposite to the usual direction after UVL in which the unaffected ear shows the greater response. The observation of a SVIN horizontal component beating toward the lesion side is probably correlated with the concomitant stimulation of the ipsilateral horizontal SCC and/or utricle
$(25,35)$ (Figure 6). The vertical most often up-beating SVIN suggests a more global stimulation than the sole anterior SCC (7). This pathology is associated with an increase sensitivity of inner ear structures to high frequencies. Our group described in SCD patients a SVIN observed up to 500 or $700 \mathrm{~Hz}$ stimulation. 

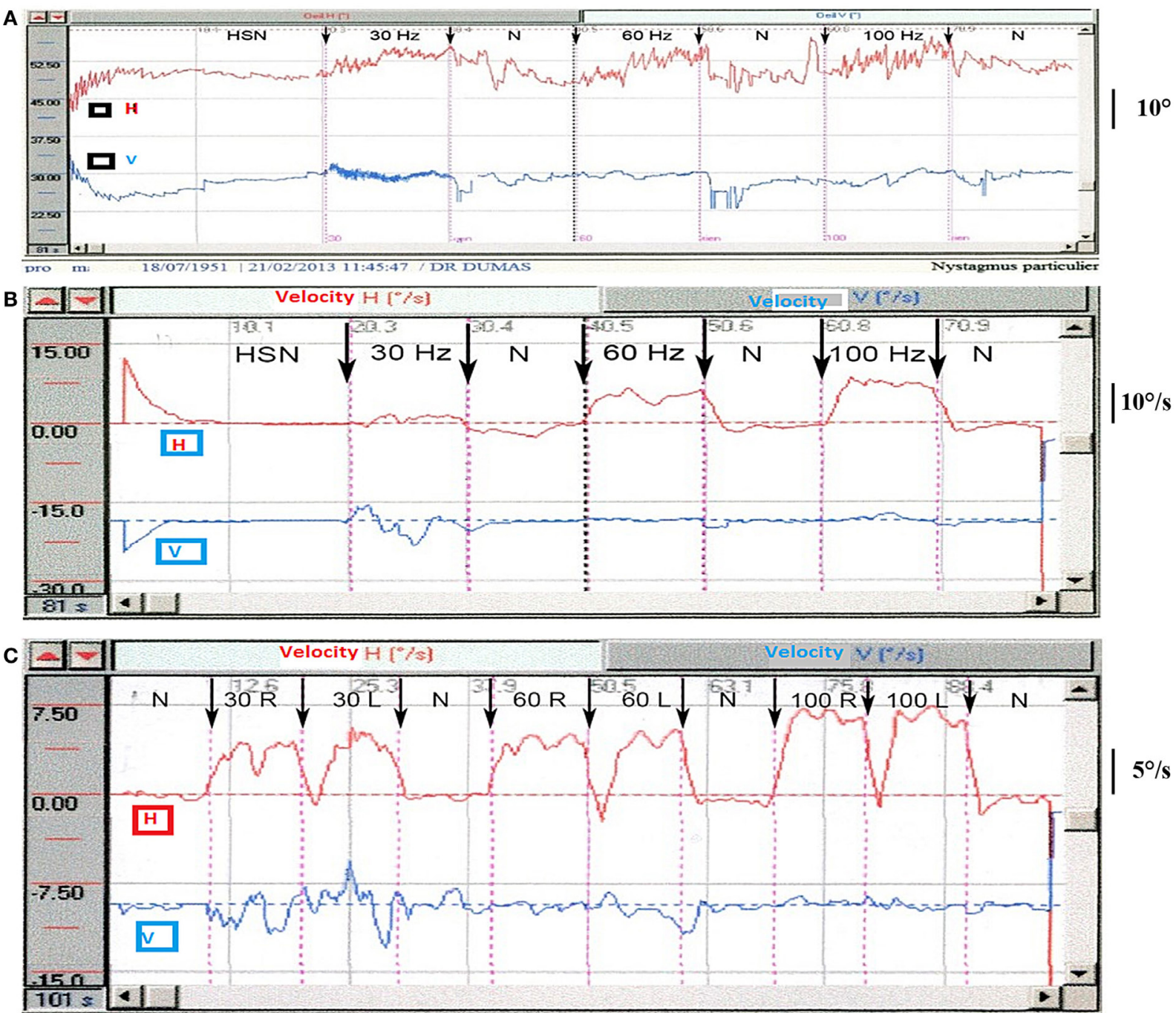

$10 \mathrm{~s}$

Time (s)

FIGURE 4 | Partial unilateral vestibular lesions [vibration-induced nystagmus (VIN) 2D recording]. (A) Example of right vestibular neuritis or acute peripheral vestibular disorder (APVD). Direct recording of head-shaking-nystagmus (HSN) and VIN at 30,60, and $100 \mathrm{~Hz}$. When skull vibration-induced nystagmus test (SVINT) is performed after the HST, it is recommended to observe an interval between the two tests (about 2 min) to avoid interference of HSN on VIN due to a possible second HSN reversal phase. (B) Same patient, right APVD: recording of the eye slow-phase velocity (SPV). (C) Right chemical labyrinthectomy (intratympanic gentamicin): 2D recording of the VIN SPV; SVINT $30 \mathrm{~Hz}$ [right mastoid (RM)-left mastoid (LM)]; $60 \mathrm{~Hz}$ (RM-LM); $100 \mathrm{~Hz}$ (RM-LM) protocol.

\section{Vestibular Neuritis (VN)}

Park et al. described SVIN in 63\% of cases $(n=38)(23)$; Nuti and Mandala observed a SVIN in $75 \%(n=28)$, a caloric hypofunction in $93 \%$, and positive HIT in $64 \%$ of cases (21). Dumas et al. observed SVIN in $90 \%$ and a caloric hypofunction in $100 \%$ $(n=18)$ (29); Karlberg et al. described in $100 \%$ of VN an ipsi lesional tonic shift of torsional eye position (13). SVIN is most often beating toward the intact side (Figures 4A,B) but a SVIN beating toward the lesion side has been described in $10 \%$ of cases $(6,27)$. To summarize, a SVIN is observed in $63-100 \%$ of cases in VN usually beating toward the intact side $(13,21,23,27,29)$ (Figure 4).

\section{Vestibular Schwannoma (VS)}

In unoperated VS, SVIN has been described in $44-78 \%$ of cases $(15,16)$.

Modugno et al. (15) observed a SVIN in $44 \%$ of his 86 cases of VS beating toward the lesion side in $26 \%$ of cases; Freyss et al. (17) observed SVIN in $65 \%$ of 51 preoperative patients while the caloric (unilateral separate ear infusion) demonstrated an hypofunction in $72 \%$ of cases and a significant vestibular asymmetry after simultaneous bilateral irrigation in $95 \%$ of cases. The SVIN beats toward the lesioned side in $6 \%$ of cases. Dumas et al. reports a SVIN in 64\%, a positive HST in $40 \%$, and caloric hypofunction in $75 \%$ of 25 VS (29). In that series, 


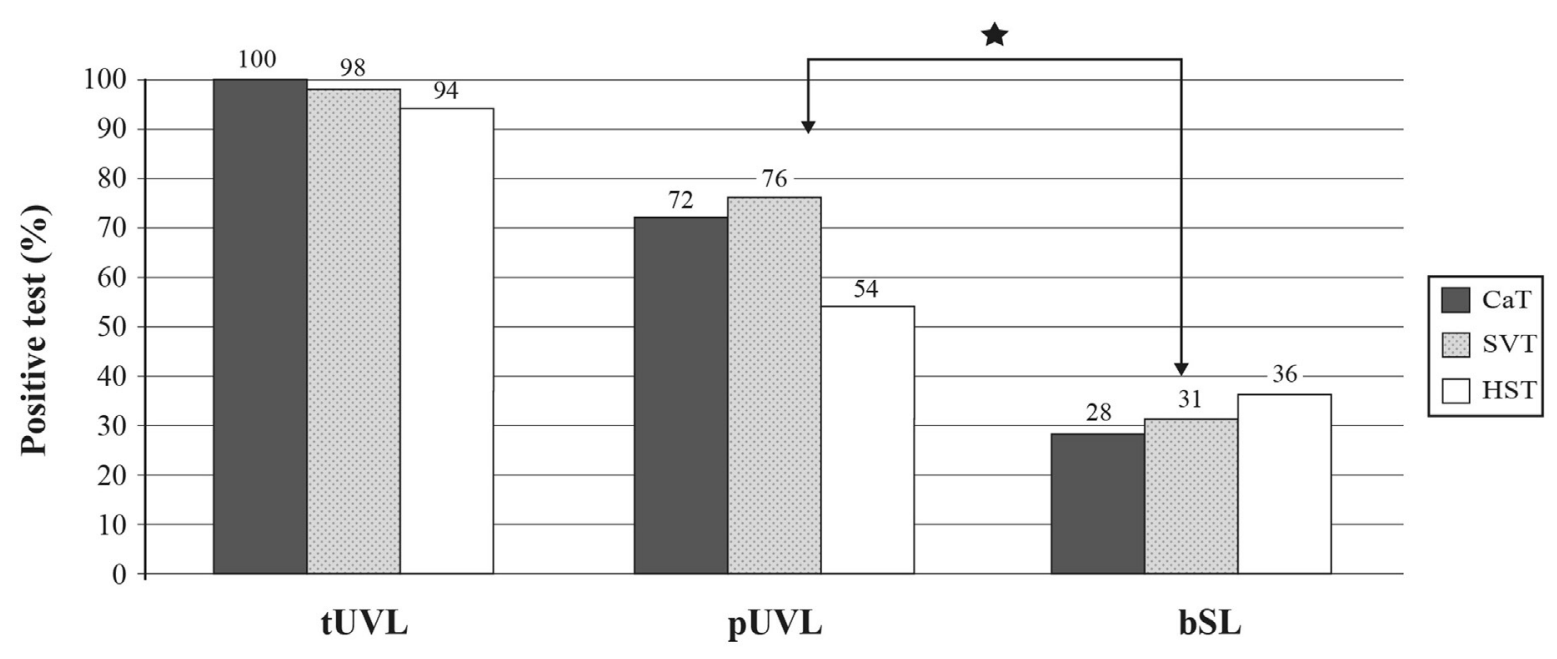

FIGURE 5 | Skull vibration-induced nystagmus test (SVINT) is more sensitive to identify peripheral than central diseases. Comparative sensitivity of caloric test (CaT), SVINT, and head-shaking test (HST) in populations of total unilateral vestibular lesions (tUVL) ( $n=131)$, of partial unilateral vestibular lesions (pUVL) $(n=78)$, and brainstem lesions (BSL) $(n=36)$. SVINT is more sensitive to reveal peripheral than central lesions $(P=0.04)$.

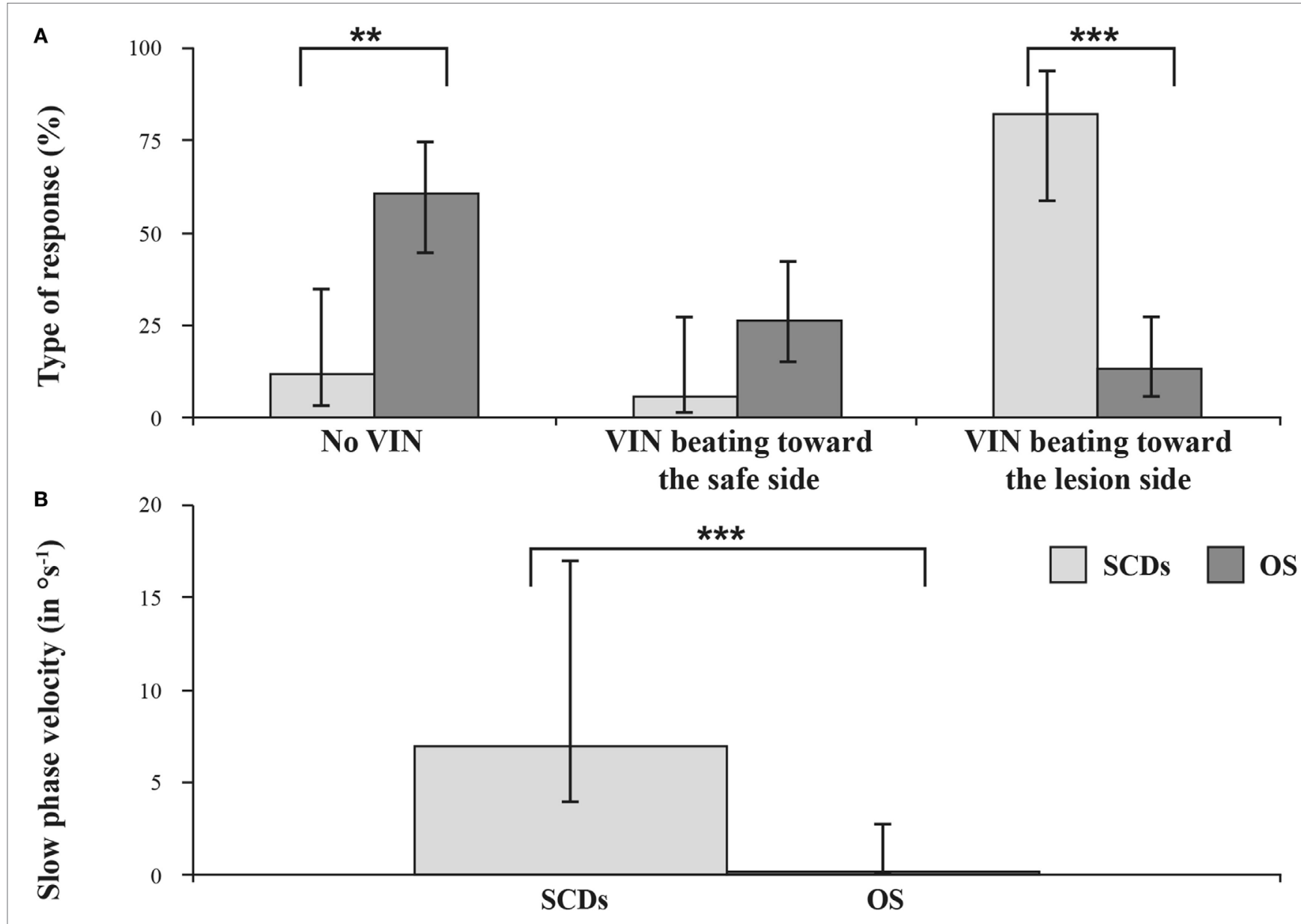

FIGURE 6 | Results in conductive hearing loss observed in unilateral SCD and otosclerosis (OS). Vibration-induced nystagmus (VIN) acts as a vestibular Weber Test. Skull vibration-induced nystagmus test (SVINT) - percentages (with 95\% confidence interval) of no VIN, VIN beating toward the healthy side, and VIN beating toward the lesion side (A) and median (with interquartile range) of the slow-phase velocity of the VIN (B) observed in superior canal dehiscence (SCD) and otosclerosis (OS) patients $\left({ }^{\star \star} P<0.001,{ }^{\star \star \star} P<0.0001\right)$. 
the test positivity depends on the VS size (SVIN is observed in only $45 \%$ of stages 1 and 2). In another study of 70 patients, a SVIN was reported in $78 \%$ while HST was positive in $51 \%$ and caloric in $83 \%$ of cases (16). A SVIN beating toward the lesion side is observed in $10 \%$ of cases (16). Hamann identifies in 15 unoperated VS (59) a SVIN in $80 \%$ of patients with unilateral lesion and notes its absence in the only case with bilateral VS. This author does not describe precisely the nystagmus direction but suggests in most cases a nystagmus beating away from the affected ear (59).

Negrevergne et al. (18) reported in 100 unoperated VS that the results of SVIN and caloric were not always positive at the same time. SVINT was positive in $72 \%$ of cases, but a SVIN beating toward the intact side or toward the lesion side was observed in $49 \%$ and in $23 \%$ of cases, respectively.

\section{Meniere's Disease (MD)}

Hong et al. (22) analyzed $52 \mathrm{MD}$ (between attacks) and observed a SVIN in $71 \%$ of cases beating toward the lesion side in $27 \%$ of cases. The SVIN observation was correlated with the severity of caloric hypofunction. Dumas et al. reported a SVIN in $71 \%$ of MD (most of them observed in a pre-attack or a period close to a recent attack) with caloric test results modified in 64\% (29). This same author described an "irritative" SVIN beating toward the lesion side in $15.5 \%$ of cases and a frequent discordance with other tests such as caloric test or HST in $30 \%$ of cases (27). Lee (45) observed a SVIN more often in the irritative phase (63\% of cases) and more rarely in quiescent periods (28\% of cases). SVIN and HSN directions are discordant in $38 \%$ of $\mathrm{MD}$ during the irritative phase. To summarize, SVIN is observed in $28-71 \%$ of MD patients cases (usually related to the proximity of an acute period) and is often of the irritative type $(22,29)$.

\section{SVIN after Intratympanic Gentamicin (ITG)} Junet et al. (70) observed an SVIN to $100 \mathrm{~Hz}$ BCV in $100 \%$ of patients treated for disabling MD by ITG after seven injections with the nystagmus beating toward the intact side. After one injection, $75 \%$ showed such an SVIN. Accordingly the strength of SVIN is a guide to the severity of the deafferentation (Figure 4C). After efficient ITG in responding patients SVIN direction is correlated and concordant with the lesion nystagmus obtained in other vestibular tests and the caloric test hypofunction.

\section{Otosclerosis (OS)}

A SVIN of low intensity is seldom observed in otosclerosis and is as often directed toward the intact as toward the lesioned side (7) (Figure 6).

\section{Benign Positional Paroxystic Vertigo (BPPV)}

In BPPV, SVINT is seldom observed (3) and is positive only in Lindsay-Hemenway syndrome (BPPV associated with a strong ipsilateral caloric hypofunction) (10).

\section{SVIN CLINICAL VALUE}

\section{A Complement to Other Vestibular Tests}

Skull vibration-induced nystagmus can be conducted where caloric tests cannot, for example, where there are middle ear malformations or tympanic membrane perforations or external acoustic meatus atresia. It is useful when caloric test results are modified after middle ear surgery (radical mastoidectomy or tympanoplasty) and show a false vestibular hyperexitability (due to thermic conduction modifications). In such cases, it can substitute for the water caloric test and give informative data. This test is less invasive and challenging for elderly, arthritic, and vascular patients than HST or HIT. In conductive hearing loss with normal tympanic membrane, it can suggest an SCD if it induces a characteristic SVIN beating toward the lesion side and still observable at high frequency stimulations. This diagnosis can be confirmed by audiometric low frequency air-bone gap (bone-conducted facilitation) for the affected side related to the existence of a third window in this pathology, the stapedial reflex preservation, and further by a dedicated (targeted) imaging. In all other peripheral pathologies associated with a vestibular hypofunction, the SVIN usually beats toward the intact side. Thus, SVIN test (SVINT) provides useful information and suggests a possible hypofunctioning side $(10,27,29)$.

Skull vibration-induced nystagmus test is useful for revealing false bilateral areflexia: such patients have no responses for caloric test and rotatory test (for low frequencies), no HSN, and no responses to vHIT for the six SCC (middle range frequencies) but show a SVIN proving that residual sensory hair cells at least on one side are still present and responding at high frequencies. Hence, a patient with a so-called bilateral vestibular areflexia should be documented not only with the caloric test, vHIT, and otolithic tests but also with SVIN (27).

Kheradmand and Zee (60) and Huh and Kim (62) mentioned SVIN as a part of other first-line examination tests in clinical practice and describe a nystagmus in UVL with the quick phase usually beating away from the paretic ear. Dumas et al. proposed SVIN since 1997 and 2000 (4, 5, 9), insisted on SVINT benefit as a simple test to reveal vestibular asymmetry and described the characteristics of the SVIN which was later designed as a suitable bedside clinical test and an adjunct to the caloric test $(4,5,10,12,14,24,26-30,47)$. This test has been proposed in occupational medicine (71). In clinical practice, SVINT may be part of a first-line bedside examination screening when combined with the HST, HIT (or VHIT), and possibly caloric test (or Barany test) $(47,72)$.

Skull vibration-induced nystagmus is a recent complementary test which allows the study of vestibular frequency spectrum at higher frequencies $(10,28,47,72)$ (Figure 7) and has extended the field of vestibular exploration which has been restricted to the low frequencies of the caloric test and rotatory test. SVINT does not replace but complements the caloric test.

\section{Inconvenience}

In case of bilateral total or symmetrical partial lesion, SVINT is negative since it does not analyze separately each side as the 


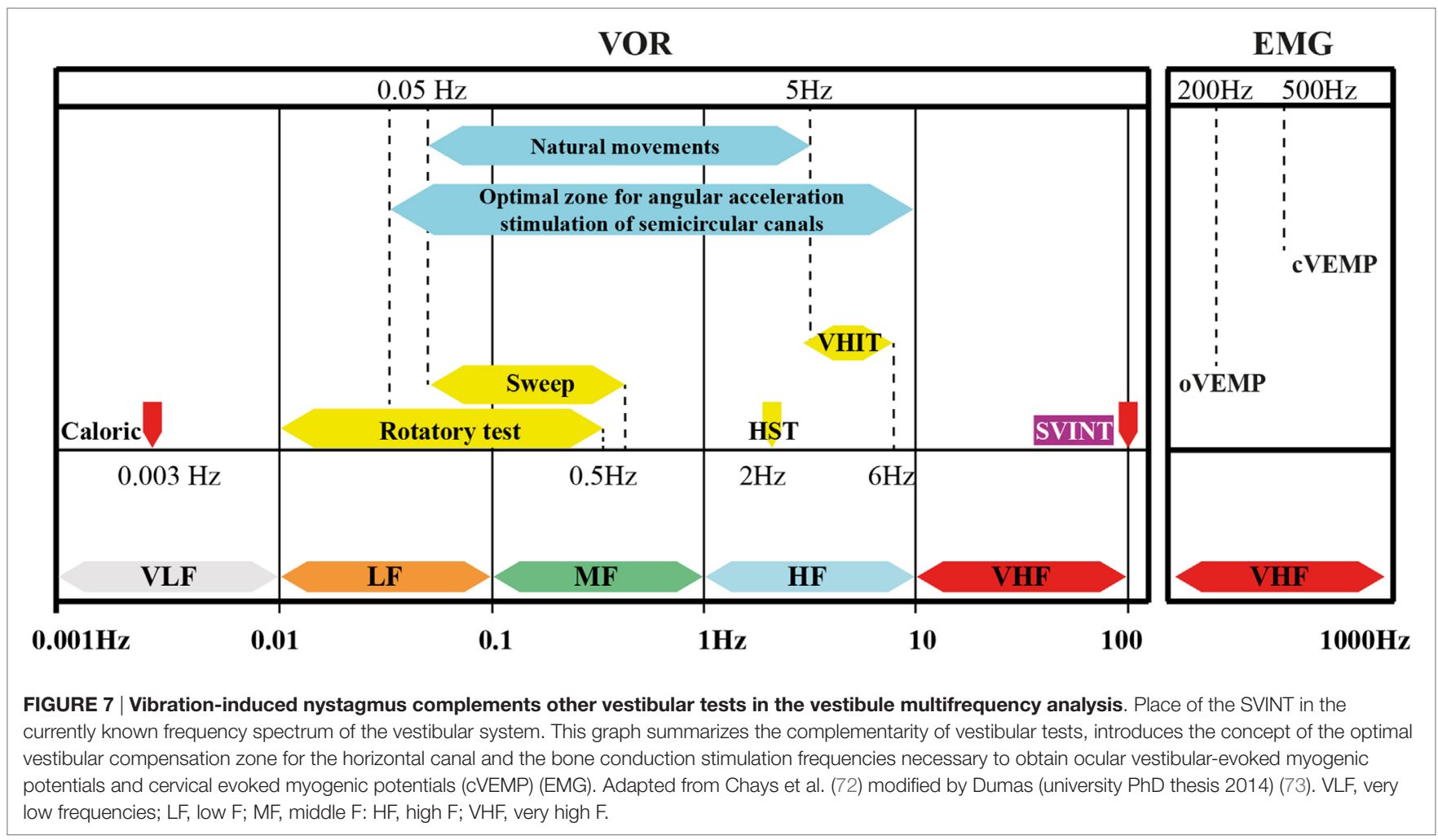

caloric test (47). This test uses extraphysiological stimulations since in daily life usual stimulations are between 0.5 and $5 \mathrm{~Hz}$ (Figure 7) (72).

\section{Tolerance and Adverse Effects}

The test acceptability has been validated in more than 18,500 subjects (73). Some patients with recent acute peripheral vestibular disorder described lateropulsion sensations (usually toward the intact side), while other subjects with SCD may report nausea when the test is repeated. These mild manifestations usually do not prevent continuation of the examination. One subject reported transient tinnitus.

The series of 18,500 patients reported in Dumas $\mathrm{PhD}$ thesis (73) noted the absence of significant side effect and signaled the advantage of this test upon HST and HIT in elderly patients with vascular problems or cervical arthritis. It is recommended to perform this test cautiously in certain situations (recently operated otosclerosis, retinal detachment, history of recent cerebral hematoma, poorly controlled anticoagulant therapy) (47).

Numerous authors using BCV do not mention any noxious effect in more restraint series $(3,11-13,23,24,64)$.

\section{CERVICAL VIBRATIONS}

Yagi and Ohyama (32) suggested in UVL patients stimulated on posterior cervical muscles that the VIN observed is the consequence of vestibular decompensation provoked by the massive proprioceptive inputs in brain stem vestibular nuclei where cervical afferents are well represented. Vibrations at $100 \mathrm{~Hz}$ have been described to correspond to optimal frequencies to stimulate muscles spindles (74). This conclusion may be moderated considering the possible concomitant stimulation of labyrinthine receptors because of vibrations diffusion (46) and since one knows that in UVL patients VIN SPV measured on Mastoid is more efficient than cervical posterior vibrations $(10,26)$.

Strupp et al. (33) explained perceptual and oculomotor effects of neck muscle vibration in $\mathrm{VN}$ as ipsilateral somatosensory substitution of vestibular function.

Iwasa et al.s (34) proposal to use vibration to determine a cervical origin in vertigo was not further confirmed. They described, in vertigo with possible cervical origin, a postural sway toward the side contralateral to the vibratory nystagmus obtained in the absence of caloric test modification. These results are difficult to interpret and not totally convincing in the perspective of the VIN after cervical stimulations as an indicator of cervical proprioceptive pathology. Popov et al. (40) demonstrated in bilateral areflexive patients that neck vibrations induce a vertical upward slow eye movement and a fast phase downward and that the propriogyral illusion is secondary to vibration-induced eye movement mediated by the cervico-ocular reflex. Kawase et al. (44) demonstrated in UVL patients (VS) that neck vibrations increase significantly SVV shift and that the presence of VIN and magnitude of SVV are correlated.

Other muscular stimulations in normal subjects either cervical or to inferior limbs have been proposed: they modify posture and head position but usually induce no nystagmus $(75,76)$. In UVL patients, cervical stimulations induce a VIN but not inferior limbs stimulations (30). 


\section{THE NEURAL BASIS-EVIDENCE FROM ANIMAL EXPERIMENTS}

The evidence for establishing the basis of SVIN comes from recordings from single primary SCC and otolithic afferents in anesthetized guinea pigs in response to $\mathrm{BCV}$ using frequencies and intensities comparable to those used in the clinical testing of SVIN in human (subjects and patients) $-100 \mathrm{~Hz}$ BCV of the skull (36-38). The predominantly horizontal component of SVIN leads to the hypothesis that it is the horizontal SCC which is activated by this stimulus.

Primary vestibular afferents with irregular resting discharge were activated during low-frequency vibration of the stereotaxic frame by a hand-held Bruel and Kjaer minishaker 4810. They were identified as canal neurons by their response to angular acceleration in canal planes or as otolith neurons by their response to static pitch stimulation, and/or by neurobiotin staining. A triaxial linear accelerometer on the skull showed that the strength of the BCV stimulation in these studies was similar to that used to generate SVIN in human patients when BCV is delivered to the mastoid by a hand-held massager or dedicated device $(3-5$, $26,27)$.

Many primary otolithic afferent neurons from the utricular or saccular macule with irregular resting discharge can be activated at low intensity by a full range of BCV frequencies from less than $100 \mathrm{~Hz}$ up to $2,000 \mathrm{~Hz}$, with a very low threshold of about $0.02 \mathrm{~g}$ peak-to-peak at $500 \mathrm{~Hz}$ (38). When activated, the cells show phase-locking of the action potential to individual cycles of the stimulus waveform, similar to that found in auditory afferents (77). At high frequencies, the neurons do not fire on every cycle but each action potential is phase-locked to approximately the same phase angle of the vibration stimulus, so every single cycle of the waveform is the effective stimulus for the vestibular receptor/afferent.

In contrast irregular horizontal SCC neurons are not activated even by high intensity (>2 g p-p) $500 \mathrm{~Hz} \mathrm{BCV} \mathrm{(78).} \mathrm{However,}$ as the frequency is decreased to around $100 \mathrm{~Hz}$, these irregular semicircular canal neurons from both the horizontal and anterior canals show activation with phase-locked firing to $100 \mathrm{~Hz}$ vibration and up to about $200-300 \mathrm{~Hz}$ (Figure 8), but no activation at higher frequencies.

This activation of SCC neurons at $100 \mathrm{~Hz}$ occurs even though the stimulus is a linear not an angular acceleration, and the frequency is above the highest reported upper frequency response of canal-cupula mechanical models of the horizontal canal (79). With phase locking, the $100 \mathrm{~Hz}$ stimulus frequency puts a limit of 100 spikes/s on the firing rate. This is above the average neural resting discharge rate of irregular semicircular canal afferents in primates (80), and such an increase in firing would also be produced by a real maintained small angular acceleration and so one would expect a horizontal eye movement response (horizontal nystagmus) to such an increased firing rate in alert animals (81).

At $500 \mathrm{~Hz}, \mathrm{BCV}$ otolith neurons are clearly activated at low threshold and high sensitivity whereas semicircular canal neurons show no change in firing rate to intense $500 \mathrm{~Hz}$ stimuli $(37,38)$. This dissociation is the reason that $500 \mathrm{~Hz} \mathrm{BCV}$ is used in specific clinical tests of otolith function in human patients $(63,82)$. However, at low frequencies around $100-200 \mathrm{~Hz}$, and at stimulus levels used clinically, both otolith and semicircular canal neurons are activated. If we could have delivered even higher amplitude linear accelerations at $500 \mathrm{~Hz}$, we may well have activated canal neurons but such very large linear accelerations are above the values used clinically and are impractical and painful for human subjects and patients and recording neurons would be beyond challenging.

\section{How Could These Results Explain the SVIN Results?}

Vibration is very efficiently transmitted through the head of both guinea pigs and humans (78). As a result, the $100 \mathrm{~Hz}$ vibration stimulus applied to one mastoid is an effective stimulus for vestibular receptors in both labyrinths and so would be expected to cause phase-locked activation in irregular afferents from both labyrinths. Presumably healthy subjects with both labyrinths intact do not show SVIN since both labyrinths will be activated and an enhanced firing rate, phase-locked to the $100 \mathrm{~Hz}$ stimulus, will occur in both vestibular nerves simultaneously and so their effects on generating horizontal eye movements presumably cancel at the level of the vestibular nuclei. In patients with UVL, the irregular horizontal canal neurons on the remaining healthy side will be activated by vibration of either mastoid, and so the increased neural firing in afferents from that healthy labyrinth will not be canceled and will result in a drive to generate a predominantly horizontal nystagmus, with quick phases directed away from the affected side. Simultaneous activation of nerves from both lateral canals in cats results in cancelation of canalinduced eye movements (83).

Anterior canal neurons are also activated by the same $100 \mathrm{~Hz}$ (and probably posterior canals also). In other words, it is likely that all canals in a labyrinth are activated by the imposed $100 \mathrm{~Hz}$ mastoid BCV. So why is the nystagmus direction horizontal? The cancelation principle implies that the eye movements induced by simultaneous anterior and posterior canal activation in the one labyrinth are opposite, and so cancel, leaving just the horizontal component driving the eye movement response.

The neural results predict the following

(1) in patients with a left UVL, the $100 \mathrm{~Hz}$ BCV stimulation will activate irregular neurons in the healthy right labyrinth, which will not be canceled by input from the affected left labyrinth. The result will be a slow-phase eye movement to the patient's left and quick phases to the patient's right, i.e., a horizontal nystagmus beating away from the affected (left) side.

(2) in patients with a dehiscence of the anterior semicircular canal in the left labyrinth - the BCV stimulation will strongly activate the irregular canal afferents from the left side and not be canceled at the vestibular nuclei by the input from the right side. This will cause a horizontal nystagmus with slow phases to the patient's right and quick phases to the patients left [i.e., a horizontal nystagmus beating toward the affected (left) side]. Moreover, in artificially created SCD, the 


\section{3-01-21, unit 1-1, ASCC}

Action potentials
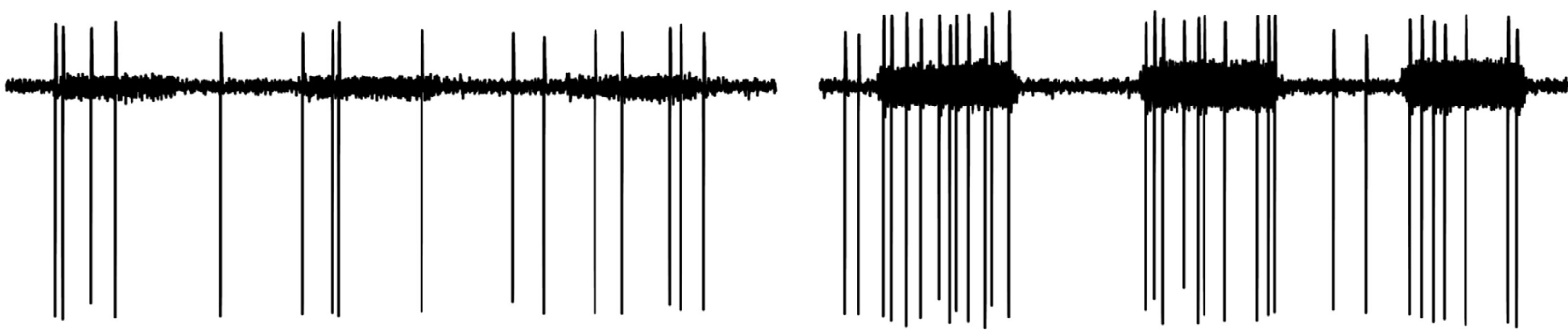

Accelerometer traces
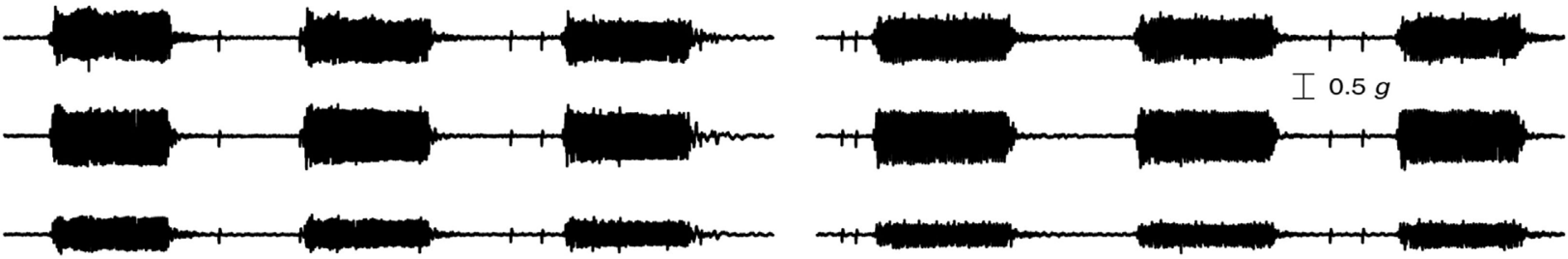

Command voltage
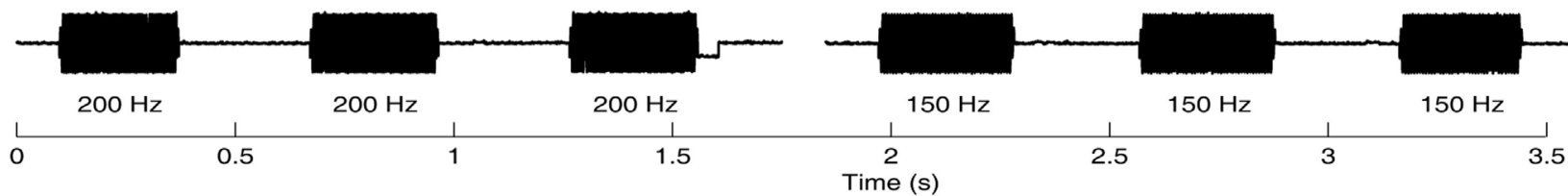

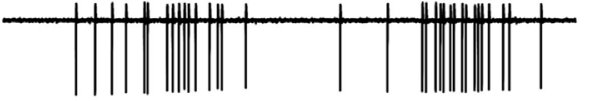

Action potentials

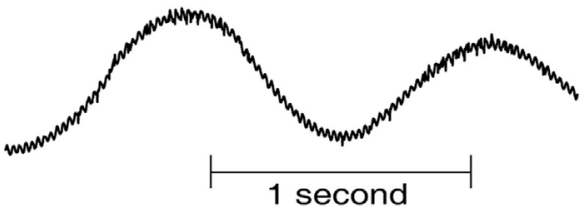

Angular velocity

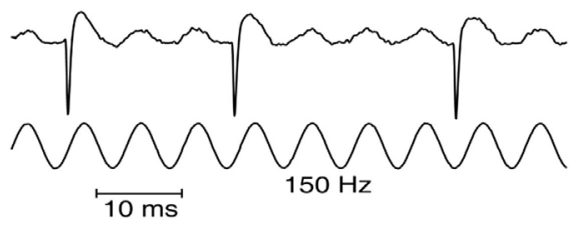

Action potentials

Command voltage

FIGURE 8 | Angular velocity data and the response to low-frequency bone-conducted vibration for an anterior semicircular canal unit. (Bottom panel) Neural activation by angular acceleration, identifying the afferent is a canal neuron. (Top Panel) Response of the same unit to bone-conducted vibration at 200 (left) and $150 \mathrm{~Hz}$ (right). As stimulus frequency is decreased the neuron shows increased firing - at $200 \mathrm{~Hz}$ there is a modest response during the stimulus but at $150 \mathrm{~Hz}$ there is a strong increase in firing tightly locked to the onset and offset of the brief stimulus.

labyrinth becomes more sensitive to high frequency stimulations for both otolith and semicircular canal receptors (84).

\section{Onset and Offset}

In human patients, the nystagmus starts abruptly at the onset of the stimulus and finishes abruptly at the termination of the stimulus - there is no after nystagmus (4, 5, 26, 29) (Figure 3). The recordings of phase-locked activation in irregular canal and otolith neurons shows precisely the same abrupt onset and termination of phase-locked neural activation, since the mechanism of this vibration-induced activation does not involve canal-cupula mechanics (35).
The absence of any evidence of velocity storage may be due to the simultaneous otolithic activation "dumping" any canalinduced nystagmus ("tilt dumping").

The response of single semicircular canal neurons to lowfrequency BCV stimulation appears to explain the major phenomena of SVIN (Box 2). Curthoys et al. (78) demonstrated in guinea pigs that at $75 \mathrm{~dB}$ and $500 \mathrm{~Hz}$ (delivered by bone-anchored vibrators) only irregular afferent fibers issuing from otolithic vestibular structures responded; there were no responses at these frequencies issuing from SCC afferents.

In a more recent work (36), the authors studied in guinea pigs responses to a wider range of frequencies and demonstrated that 


\section{BOX 2 | Summary.}

1. Why SVIN occurs in patients with asymmetric vestibular function but not in healthy subjects: $100 \mathrm{~Hz}$ BCV activates semicircular canal neurons in intact (normally encased) labyrinths, and in healthy subjects the simultaneous neural input from both labyrinths would be expected to cancel, whereas in unilateral patients the input from the healthy side is unopposed so cancelation does not occur.

2. Why the nystagmus direction is horizontal in UVL patients: the vibration probably activates sensitive canal neurons in all canals, in both labyrinths, but the anterior and posterior canal inputs in each labyrinth will cancel, leaving just the horizontal canal activation driving the eye movement.

3. Why $100 \mathrm{~Hz}$ BCV mastoid stimulation of patients with UVL causes nystagmus with quick phases beating away from the affected side: the unopposed neural drive from the intact labyrinth will cause slow phases away from the healthy side and quick phases toward the healthy side (i.e., away from the affected side).

4. Why $100 \mathrm{~Hz}$ BCV mastoid stimulation of patients with SCD causes nystagmus with quick phases beating toward the affected side: the neural drive from the side with the SCD will have lower threshold and higher firing rate and so will not be fully canceled by the activation from the healthy ear resulting in slow phases away from the affected side and quick phases toward the affected side.

5. Why these respective responses in patients are independent of which mastoid is stimulated: the vibration stimulation is conducted so effectively to both labyrinths, independently of which side is stimulated.

6. Why the onset and offset of the nystagmus is so abrupt, unlike other nystagmus attributed to horizontal canal activation by angular acceleration: the vibration stimulus causes immediate phase-locked activation of canal neurons which ceases at stimulus offset.

7. Why high frequency vibrations at $100 \mathrm{~Hz}$ which are beyond the mechanical cut off frequencies of canal mechanism: BCV induces inner ear fluid displacements which deflect type I receptors and so activates irregular afferent neurons.

at $100 \mathrm{~Hz}$ in normally encased labyrinths both canal and otolithic irregular fibers were activated. Lower stimulus intensity (in g) is, however, required to elicit responses from otolithic structures than from canals. For frequencies at $500 \mathrm{~Hz}$ or higher, only otolithic afferents from the striola region of utricular or saccular macula were activated $(36,78)$.

Vibration-induced nystagmus requires not only integrity of the peripheral end organ (type 1 inner ear hair cells), afferent neurons with irregular discharges, and integration in the vestibular nucleus for production of the slow phase but also structures of the brain stem to restore the eye position by quick phases (pontine reticula formation). Clinical interpretation of VIN in term of topography and side of a lesion needs a careful analysis and we emphasize that although SVIN is robust and the $100-\mathrm{Hz}$ mastoid vibration stimulus is superficially simple, care must be taken with patient testing, stimulus presentation, response measurement, and the interpretation of the results (Box 3 ).

\section{CONCLUSION}

Skull vibration-induced nystagmus test, a recent, robust, noninvasive examination test, has opened a new area of vestibular exploration as it allows without side effects a simple non-invasive, rapid clinical test to vestibular high frequencies. SVINT is a useful tool to indicate a lesion side and reveals instantaneously, even in chronic or compensated patients, a SVIN in case of

\section{BOX 3 | SVIN validity criteria.}

The induced nystagmus starts with stimulation, stops with its withdrawal, and does not present any secondary reversal. It is sustained, reproducible, and beats in the same direction either after left and/or right mastoid (RM) process stimulation, is often less intense or absent after vertex stimulation (except in case of superior SCD). Nystagmus is usually absent or discordant in subjects with no vestibular disorders: in $10 \%$ of cases, false-positive nystagmus is observed at $60 \mathrm{~Hz}$ with right-beating nystagmus on the RM and left-beating nystagmus on the left mastoid (inconsistent directions). A SVIN slow-phase velocity SPV greater than $2 \%$ is also required to validate the test.

vestibular asymmetry as a vestibular Weber test. SVINT is a reliable, fast, first-line test. The optimal frequency to induce a SVIN is $100 \mathrm{~Hz}$.

Skull vibration-induced nystagmus test is useful to complement information of other common vestibular tests in the multifrequency analysis of vestibular function. Yet, it gives no specific information on vestibular pathways exact topographic alteration and reveals modifications related with a lesion located in any point of the vestibulo-ocular reflex pathway. Noteworthy, it is significantly more sensitive to reveal peripheral than central lesions.

Skull vibration-induced nystagmus test is not influenced by vestibular compensation and could be advisable as an additional data and an adjunct in forensic or occupational medicine. It brings complementary information to classical SCC test explorations, cVEMP, and oVEMP. Its use in clinical practice seems to predict a wider development as a future promising first-line test.

\section{AUTHOR NOTES}

The skull vibration-induced nystagmus test was the subject of the $\mathrm{PhD}$ thesis entitled "Influence of vibratory stimulation applied to the skull and neck muscles on equilibrium function. Physiological interpretations and applications to pathology. Development and validation of a new vestibular investigation test: the skull vibration-induced nystagmus test or Dumas test" presented at the University of Lorraine (Nancy), September 18, 2014. Thesis Jury Members: S. Caudron, France; A. Charpiot, France; N. Deggouj, Belgium; P. Denise, France; H. Kingma, The Netherlands; M. Magnusson, Sweden; P. Perrin, France; S. Schmerber, France; D. Vibert, Switzerland.

\section{AUTHOR CONTRIBUTIONS}

All authors listed, have made substantial, direct and intellectual contribution to the work, and approved it for publication.

\section{ACKNOWLEDGMENTS}

The authors thank the UEM CHU Grenoble, the institute of health Luxembourg, and the DRCI Grenoble for their scientific support; Mrs. Hernandez of the Biomedical Department Grenoble for the material supply; P. Jousse from the Neuroradiology Department for drawings and figures. 


\section{REFERENCES}

1. Von-Bekesy G. Über akustishe Reizung des Vestibularapparates. Arch Ges Physiol (1935) 236:59-72. doi:10.1007/BF01752324

2. Lucke K. [A vibratory stimulus of $100 \mathrm{~Hz}$ for provoking pathological nystagmus (author's transl)]. Z Laryngol Rhinol Otol (1973) 52(10):716-20.

3. Hamann KF, Schuster EM. Vibration-induced nystagmus - a sign of unilateral vestibular deficit. ORL J Otorhinolaryngol Relat Spec (1999) 61(2):74-9. doi:10.1159/000027645

4. Dumas G, Michel J, Lavieille JP, Charachon R, Ouedraogo E. [Clinical value of the cranial vibratory test. A 3D analysis of the nystagmus]. J Fr ORL (1999) 48:13-21.

5. Dumas G, Michel J, Lavieille JP, Ouedraogo E. [Semiologic value and optimum stimuli trial during the vibratory test: results of a $3 \mathrm{D}$ analysis of nystagmus]. Ann Otolaryngol Chir Cervicofac (2000) 117(5):299-312.

6. Dumas G, Perrin P, Morel N, N'Guyen DQ, Schmerber S. [Skull vibratory test in partial vestibular lesions - influence of the stimulus frequency on the nystagmus direction]. Rev Laryngol Otol Rhinol (Bord) (2005) 126(4):235-42.

7. Dumas G, Lion A, Karkas A, Perrin P, Perottino F, Schmerber S. Skull vibration-induced nystagmus test in unilateral superior canal dehiscence and otosclerosis: a vestibular Weber test. Acta Otolaryngol (2014) 134(6):588-600. doi:10.3109/00016489.2014.888591

8. Young ED, Fernandez C, Goldberg JM. Responses of squirrel monkey vestibular neurons to audio-frequency sound and head vibration. Acta Otolaryngol (1977) 84(5-6):352-60. doi:10.3109/00016487709123977

9. Dumas G, Michel J. Valeur sémeiologique du test de vibration osseux crânien. In: IPSEN, editor. XXXI ème Symposium International d'Otoneurologie. Liège (1997).

10. Dumas G, De Waele C, Hamann KF, Cohen B, Negrevergne M, Ulmer E, et al. [Skull vibration induced nystagmus test]. Ann Otolaryngol Chir Cervicofac (2007) 124(4):173-83. doi:10.1016/j.aorl.2007.05.001

11. Lackner JR, Graybiel A. Elicitation of vestibular side effects by regional vibration of the head. Aerosp Med (1974) 45(11):1267-72.

12. Ohki M, Murofushi T, Nakahara H, Sugasawa K. Vibration-induced nystagmus in patients with vestibular disorders. Otolaryngol Head Neck Surg (2003) 129(3):255-8. doi:10.1016/S0194-5998(03)00529-1

13. Karlberg M, Aw ST, Black RA, Todd MJ, MacDougall HG, Halmagyi GM. Vibration-induced ocular torsion and nystagmus after unilateral vestibular deafferentation. Brain (2003) 126(Pt 4):956-64. doi:10.1093/brain/awg091

14. Dumas G, Lavieille J, Schmerber S, Sauvage J. Le test vibratoire osseux crânien. Rev SFORL (2004) 82:8-14.

15. Modugno G, Brandolini C, Piras G, Raimondi M, Ferri G. Bone VibrationInduced Nystagmus (VIN) Is Useful in Diagnosing Vestibular Schwannoma (VS). Sixth International Conference on Acoustic Neuroma; 2011. Los Angeles: International Conference on Acoustic Neuroma (2011).

16. Dumas G, Karkas A, Schmerber S. Skull high-frequency vibration-induced nystagmus test for vestibular function assessment in vestibular schwannoma. In: Neuroma I, editor. Sixth International Conference on Acoustic Neuroma; 2011. Los Angeles (2011).

17. Freyss G, De-Waele C, Ledjedel S. Efficacité comparative des explorations vestibulaires caloriques (épreuves unilatérales et bilatérales simultanées) et vibratoires dans la détection des neurinomes de lacoustique. In: IPSEN, editor. XXXVI ème Symposium de la Société Internationale d'Otoneurologie; 2006. Paris (2006).

18. Negrevergne M, Ribeiro S, Moraes CL, Maunsell R, Morata GC, Darrouzet $\mathrm{V}$. [Video-nystagmography and vibration test in the diagnosis of vestibular schwannoma. Review of 100 cases]. Rev Laryngol Otol Rhinol (Bord) (2003) 124(2):91-7.

19. Koo JW, Kim JS, Hong SK. Vibration-induced nystagmus after acute peripheral vestibular loss: comparative study with other vestibulo-ocular reflex tests in the yaw plane. Otol Neurotol (2011) 32:466-71. doi:10.1097/ MAO.0b013e31820d9685

20. Xie S, Guo J, Wu Z, Qiang D, Huang J, Zheng Y, et al. Vibration-induced nystagmus in patients with unilateral peripheral vestibular disorders. Indian J Otolaryngol Head Neck Surg (2013) 65(4):333-8. doi:10.1007/ s12070-013-0638-6

21. Nuti D, Mandala M. Sensitivity and specificity of mastoid vibration test in detection of effects in vestibular neuritis. Acta Otorhinolaryngol Ital (2005) 25:271-6.
22. Hong SK, Koo JW, Kim JS, Park MH. Implication of vibration induced nystagmus in Menière's disease. Acta Otolaryngol Suppl (2007) 127(558):128-31. doi:10.1080/03655230701625019

23. Park H, Hong SC, Shin J. Clinical significance of vibration-induced nystagmus and head-shaking nystagmus through follow-up examinations in patients with vestibular neuritis. Otol Neurotol (2008) 29(3):375-9. doi:10.1097/ MAO.0b013e318169281f

24. Park H, Lee Y, Park M, Kim J, Shin J. Test-retest reliability of vibration-induced nystagmus in peripheral dizzy patients. J Vestib Res (2010) 20(6):427-31. doi:10.3233/VES-2010-0389

25. Park JH, Kim HJ, Kim JS, KooJ W. Costimulation oft he horizontal semicircular canal during skull vibrations in superior canal dehiscence syndrome. Audiol Neurootol (2014) 19:175-83. doi:10.1159/000358002

26. Dumas G, Perrin P, Schmerber S. Nystagmus induced by high frequency vibrations of the skull in total unilateral peripheral vestibular lesions. Acta Otolaryngol (2008) 128:255-62. doi:10.1080/00016480701477677

27. Dumas G, Karkas A, Perrin P, Chahine K, Schmerber S. High-frequency skull vibration-induced nystagmus test in partial vestibular lesions. Otol Neurotol (2011) 32:1291-301. doi:10.1097/MAO.0b013e31822f0b6b

28. Dumas G, Schmerber S, Lavieille JP. [Nystagmus and vibratory test: evidence for mechanism. Material conditions and methods in the fast detection of unilateral vestibular lesions]. Ann Otolaryngol Chir Cervicofac (2003) 120(5):286-95.

29. Dumas G, De-Waele C, Tran-Ba-Huy P, Chays A. Test vibratoire osseux crânien. In Electrophysiologie en ORL. Paris: Société Française d'Oto-rhino-laryngologie et de Chirurgie de la Face et du Cou (2008). p. 154-9.

30. Dumas G, Lion A, Gauchard G, Herpin G, Magnusson M, Perrin P. Clinical interest of postural and vestibulo-ocular reflex changes induced by cervical muscles and skull vibration in compensated unilateral vestibular lesion patients. J Vestib Res (2013) 23:41-9. doi:10.3233/VES-130468

31. Magnusson M, Andersson G, Gomez S, Johansson R, Martensson A, Karlberg $M$, et al. Cervical muscle afferents play a dominant role over vestibular afferents during bilateral vibration of neck muscles. J Vestib Res (2006) 16(3):127-36

32. Yagi T, Ohyama Y. Three-dimensional analysis of nystagmus induced by neck vibration. Acta Otolaryngol (1996) 116(2):167-9. doi:10.3109/ 00016489609137815

33. Strupp M, Arbusow V, Dieterich M, Sautier W, Brandt T. Perceptual and oculomotor effects of neck muscle vibration in vestibular neuritis. Ipsilateral somatosensory substitution of vestibular function. Brain (1998) 121(Pt 4):677-85. doi:10.1093/brain/121.4.677

34. Iwasa $\mathrm{H}$, Yagi $\mathrm{T}$, Kamio $\mathrm{T}$. Diagnostic significance of neck vibration for the cervical vertigo. Adv Otorhinolaryngol (1983) 30:268-70.

35. Curthoys IS, Grant JW. How does high frequency sound or vibration activate vestibular receptors? Exp Brain Res (2015) 233(3):691-9. doi:10.1007/ s00221-014-4192-6

36. Curthoys IS, Vulovic V, Pogson J, Sokolic L. Responses of Guinea Pig Primary Vestibular Afferents to Low Frequency $(50-100 \mathrm{~Hz})$ Bone Conducted Vibration (BCV) - The Neural Basis of Vibration Induced Nystagmus. Program No. 574.062012 Neuroscience Meeting Planner. New Orleans, LA: Society for Neuroscience (2013)

37. Curthoys IS, Vulovic V, Burgess AM, Manzari L, Sokolic L, Pogson J, et al. Neural basis of new clinical vestibular tests: otolithic neural responses to sound and vibration. Clin Exp Pharmacol Physiol (2014) 41:371-80. doi:10.1111/1440-1681.12222

38. Curthoys IS, Vulovic V, Burgess AM, Sokolic L, Goonetilleke SC. The response of guinea pig primary utricular and saccular irregular neurons to bone-conducted vibration (BCV) and air-conducted, sound (ACS). Hear Res (2016) 331:131-43. doi:10.1016/j.heares.2015.10.019

39. Bozovic D, Hudspeth AJ. Hair-bundle movements elicited by transepithelial electrical stimulation of hair cells in the sacculus of the bullfrog. Proc Natl Acad Sci U S A (2003) 100(3):958-63. doi:10.1073/pnas.0337433100

40. Popov KE, Lekhel H, Faldon M, Bronstein AM, Gresty MA. Visual and oculomotor responses induced by neck vibration in normal subjects and labyrithin defective patients. Exp Brain Res (1999) 128(3):343-52. doi:10.1007/ s002210050854

41. White JA, Hughes GB, Ruggieri PN. Vibration-induced nystagmus as an office procedure for the diagnosis of superior semicircular canal dehiscence. Otol Neurotol (2007) 28(7):911-6. doi:10.1097/MAO.0b013e31812f7222 
42. Manzari L, Modugno GC, Brandolini C, Pirodda A. Bone vibration-induced nystagmus is useful in diagnosing superior semicircular canal dehiscence. Audiol Neurootol (2008) 13(6):379-87. doi:10.1159/000148201

43. Aw ST, Aw GE, Todd MJ, Bradshaw AP, Halmagyi GM. Three-dimensional vibration-induced vestibulo-ocular reflex identifies vertical semicircular canal dehiscence. J Assoc Res Otolaryngol (2011) 12(5):549-58. doi:10.1007/ s10162-011-0274-3

44. Kawase T, Maki A, Takata Y, Miyazaki H, Kobayashi T. Effects of neck muscle vibrations on subjective visual vertical comparative effects on nystagmus. Eur Arch Otorhino Laryngol (2011) 268(6):823-7. doi:10.1007/s00405-010-1467-9

45. Lee S-U, Kee HJ, Sheen SS, Choi BY, Koo JW, Kim J-S. Head-shaking and vibration-induced nystagmus duringan between the attacks of unilateral Menière's disease. Otol Neurotol (2015) 36(5):865-72. doi:10.1097/ MAO.0000000000000743

46. Dumas G, Lion A, Perrin P, Ouedraogo E, Schmerber S. Topographic analysis of the skull vibration-induced nystagmus test with piezoelectric accelerometers and force sensors. Neuroreport (2016) 27(5):318-22. doi:10.1097/ WNR.0000000000000539

47. Dumas G, Perrin P, Ouedraogo E, Schmerber S. How to perform the skull vibration induced nystagmus test (SVINT). Eur Ann Otorhinolaryngol Head Neck Dis (2016) 133(5):343-8. doi:10.1016/j.anorl.2016.04.002

48. Franke E. Response of the human skull to mechanical vibrations. J Acoust Soc Am (1956) 28:1277-84. doi:10.1121/1.1908622

49. Jahn AF, Tonndorf J. Lateralization of bone-conducted sounds. Am J Otolaryngol (1982) 3(2):133-40. doi:10.1016/S0196-0709(82)80044-6

50. Stenfelt S, Goode RL. Bone-conducted sound: physiological and clinical aspects. Otol Neurotol (2005) 26(6):1245-61. doi:10.1097/01.mao.0000 187236.10842.d5

51. Wever E, Bray C. The nature of bone conduction as shown in the electrical response of the cochlea. Ann Otol Rhinol Laryngol (1936) 45:822-30. doi:10.1177/000348943604500323

52. Stenfelt S, Puria S, Hato N, Goode RL. Basilar membrane and osseous spiral lamina motion in human cadavers with air and bone conduction stimuli. Hear Res (2003) 181(1-2):131-43. doi:10.1016/S0378-5955(03)00183-7

53. Nolan M, Lyon DJ. Transcranial attenuation in bone conduction audiometry. J Laryngol Otol (1981) 95(6):597-608. doi:10.1017/S0022215100091155

54. Kirikae I. An experimental study on the fundamental mechanism of bone conduction. Acta Otolaryngol Suppl (1959) 145:1-111.

55. Von-Bekesy G. Zur Theorie des Hörens bei der Schallaufnahme durch Knockenleitung. Ann Physik (1932) 132(13):111-36. doi:10.1002/andp. 19324050109

56. Richter U, Brinkmann K. Threshold of hearing by bone conduction. A contribution to international standardization. Scand Audiol (1981) 10(4):235-7. doi:10.3109/01050398109076186

57. Tonndorf J. Compressional bone conduction in cochlear models. J Acoust Soc Am (1962) 34:1127-31. doi:10.1121/1.1918259

58. Sohmer H, Freeman S, Geal-Dor M, Adelman C, Savion I. Bone conduction experiments in humans, a fluid pathway from bone to ear. Hear Res (2000) 146:81-8. doi:10.1016/S0378-5955(00)00099-X

59. Hamann KF. Le Nystagmus de Vibration vis à vis du Neurinome de lacoustique. In: IPSEN, editor. XXXVI ime Symposium de la Société Internationale d'Otoneurologie de langue Française 2002. 24-25 Mai. Marrakech (2002). p. 47.

60. Kheradmand A, Zee D. The bedside examination of the vestibulo-ocular reflex (VOR): an update. Rev Neurol (2012) 168:710-9. doi:10.1016/j. neurol.2012.07.011

61. Dumas G, Schmerber S. Cavernous haemangiomas: hearing and vestibular inaugural symptoms. Ann Otolaryngol Chir Cervicofac (2004) 121(5):272-81. doi:10.1016/S0003-438X(04)95520-X

62. Huh YE, Kim JS. Bedside evaluation of dizzy patients. J Clin Neurol (2013) 9:203-13. doi:10.3988/jen.2013.9.4.203

63. Curthoys IS. The interpretation of clinical tests of peripheral vestibular function. Laryngoscope (2012) 122:1342-52. doi:10.1002/lary.23258

64. Ulmer E, Chays A, Bremond G. [Vibration-induced nystagmus: mechanism and clinical interest]. Ann Otolaryngol Chir Cervicofac (2004) 121(2):95-103. doi:10.1016/S0003-438X(04)95495-3

65. Minor LB, Solomon D, Zinreich JS, Zee DS. Sound- and/or pressure-induced vertigo due to bone dehiscence of the superior semicircular canal. Arch Otolaryngol Head Neck Surg (1998) 124(3):249-58.
66. Minor LB. Superior canal dehiscence syndrome. Am J Otol (2000) 21(1):9-19. doi:10.1016/S0196-0709(00)80105-2

67. Rosowski JJ, Songer JE, Nakajima HH, Brinsko KM, Merchant SN. Clinical, experimental, and theoretical investigations of the effect of superior semicircular canal dehiscence on hearing mechanisms. Otol Neurotol (2004) 25(3):323-32. doi:10.1097/00129492-200405000-00021

68. Songer JE, Rosowski JJ. The effect of superior canal dehiscence on cochlear potential in response to air-conducted stimuli in chinchilla. Hear Res (2005) 210(1-2):53-62. doi:10.1016/j.heares.2005.07.003

69. Songer JE, Rosowski JJ. A mechano-acoustic model of the effect of superior canal dehiscence on hearing in chinchilla. J Acoust Soc Am (2007) 122(2):943-51. doi:10.1121/1.2747158

70. Junet P, Karkas A, Dumas G, Quesada JL, Schmerber S. Vestibular results after intratympanic gentamicin therapy in disabling Menière's disease. Eur Arch Otolaryngol (2016) 273(10):3011-8. doi:10.1007/s00405-015-3889-x

71. Beatrice F, Karkas A, Bucolo S, Palermo A, Perottino F, Lion A, et al. Benefit of skull vibration-induced nystagmus test in occupational medicine. Rev Laryngol Otol Rhinol (2014) 135(1):1-6.

72. Chays A, Florent A, Ulmer E. Les Vertiges. Paris: Masson (2004). 213 p.

73. Dumas G. Influence of Vibratory Stimulations Applied to Skull and Cervical Muscles on Equilibrium Function. Physiological Interpretation and Applications in Pathology. Development and Validation of a New Vestibular Test: The Skull Vibration Induced Nystagmus Test or Dumas Test. Ph.D. thesis, University of Lorraine, Perrin P, Schmerber S Thesis directors (2014).

74. Perrin P, Lestienne F. In: Masson, editor. Mécanismes de léquilibration humaine. Exploration fonctionnelle, application au sport et à la rééducation. Paris, Milan, Barcelona (1994). 168 p.

75. Roll JP, Vedel JP, Bibot E. Eye, head and skeletal muscle spindle feedback in the elaboration of body references. Prog Brain Res (1989) 80:113-23. doi:10.1016/ S0079-6123(08)62204-9

76. Dumas G. Validation d'un test de léquilibration chez des sportifs de haut niveau. Master's thesis, Nancy, UFR en Sciences et Techniques des Activités Physiques et Sportives, Nancy I (2001).

77. Rose JE, Brugge JF, Anderson DJ, Hind JE. Phase-locked response to low-frequency tones in single auditory nerve fibers of the squirrel monkey. J Neurophysiol (1967) 30(4):769-93.

78. Curthoys IS, Kim J, McPhedran SK, Camp AJ. Bone conducted vibration selectively activates irregular primary otolithic vestibular neurons in the guinea pig. Exp Brain Res (2006) 175:256-67. doi:10.1007/s00221-0060544-1

79. Hartmann R, Klinke R. Discharge properties of afferent-fibers of the goldfish semicircular canal with high-frequency stimulation. Pflugers Arch (1980) 388:111-21. doi:10.1007/bf00584116

80. Haque A, Angelaki DE, Dickman JD. Spatial tuning and dynamics of vestibular semicircular canal afferents in rhesus monkeys. Exp Brain Res (2004) 155:81-90. doi:10.1007/s00221-003-1693-0

81. Waespe W, Henn V. Velocity response of vestibular nucleus neurons during vestibular, visual, and combined angular-acceleration. Exp Brain Res (1979) 37:337-47. doi:10.1007/BF00237718

82. Iwasaki S, Smulders YE, Burgess AM, McGarvie LA, Macdougall HG, Halmagyi GM, et al. Ocular vestibular evoked myogenic potentials to bone conducted vibration of the midline forehead at $\mathrm{Fz}$ in healthy subjects. Clin Neurophysiol (2008) 119:2135-47. doi:10.1016/j.clinph.2008.05.028

83. Cohen B, Suzuki J-I, Bender MB. Eye movements from semicircular canal nerve stimulation in the cat. Ann Otol Rhinol Laryngol (1964) 73:153-69. doi: $10.1177 / 000348946407300116$

84. Curthoys IS. The new vestibular stimuli: sound and vibration-anatomical, physiological and clinical evidence. Exp Brain Res (2017). doi:10.1007/ s00221-017-4874-y

Conflict of Interest Statement: IC is an unpaid consultant to GN Otometrics. The other authors declare no conflict of interest.

Copyright $\odot 2017$ Dumas, Curthoys, Lion, Perrin and Schmerber. This is an open-access article distributed under the terms of the Creative Commons Attribution License (CC BY). The use, distribution or reproduction in other forums is permitted, provided the original author(s) or licensor are credited and that the original publication in this journal is cited, in accordance with accepted academic practice. No use, distribution or reproduction is permitted which does not comply with these terms. 